\title{
Respondem os políticos a questionamentos dos eleitores? Um experimento controlando os incentivos de mensagem, período e meio
}

\author{
Márcio Cunha Carlomagno ${ }^{1}$ \\ Sergio Soares Braga² \\ Rafael Cardoso Sampaio ${ }^{3}$
}

\begin{abstract}
Este artigo apresenta os resultados de um experimento conduzido entre setembro de 2014 e julho de 2015 para verificar a responsividade dos parlamentares brasileiros a questões enviadas por cidadãos, sob distintas condições. Para isso, foram enviadas quatro rodadas de mensagens, ao longo do período, aos 513 deputados federais, controlando os incentivos. Testamos três fatores: a) o conteúdo da mensagem (potencial eleitor versus uma questão sobre votação de projeto de lei em plenário); b) o período em que a mensagem foi enviada (eleitoral e não eleitoral); c) a plataforma por meio da qual a mensagem foi enviada (e-mail e mídias sociais). Em geral, a taxa de respostas é muito pequena, indicando a baixa responsividade digital dos parlamentares brasileiros. O modelo de regressão logística demonstra que "período eleitoral" não exerce grande influência, que "incentivos do conteúdo da mensagem" aumentam em dez vezes a probabilidade de resposta e que "mensagens enviadas via mídias sociais" aumentam em nove vezes a probabilidade de resposta. Discutimos os resultados sob a luz da teoria dos incentivos políticos e da ampliação das possibilidades de accountability trazidas pelas ferramentas de comunicação política online. Acreditamos que a pesquisa abre caminho para futuras abordagens experimentais nessa seara.
\end{abstract}

Palavras-chave: experimento; legislativo; interatividade; responsividade; Facebook

\section{Introdução}

Muito se fala sobre as supostas promessas não cumpridas pela internet, ou ainda, sobre como a internet não trouxe os (benéficos) impactos políticos que dela se esperavam, como, por exemplo: uma esfera civil informada; a liberação do polo de emissão que, potencialmente, transformaria os cidadãos em ativos produtores de informação, desafiando a lógica unilateral dos meios massivos de comunicação, e criaria uma espécie de rede não hierarquizada, descentralizada; e as possibilidades de uma maior e mais

\footnotetext{
1 Universidade Federal do Paraná, Curitiba (PR), Brasil. E-mail: <mccarlomagno@gmail.com>. Orcid: <https://orcid.org/0000-0002-1145-1523>.

2 Universidade Federal do Paraná, Curitiba (PR), Brasil. E-mail: <sssbraga@gmail.com>. Orcid: <http://orcid.org/0000-0003-3397-0575>.

3 Universidade Federal do Paraná, Curitiba (PR), Brasil. E-mail: <cardososampaio@gmail.com>. Orcid: <https://orcid.org/0000-0001-5176-173X>.
} 
frequente participação cidadã nas tomadas de decisões públicas que seriam enormemente facilitadas pelos meios digitais, o que, já sabemos, ocorreu de fato, mas não na medida e da maneira que era pregado (Hindman, 2009). Dentre as promessas, uma frequentemente relatada e especialmente verificada é a interatividade, a rigor, um aumento da interação entre cidadãos e agentes e instituições políticas.

A premissa é simples: nas sociedades massivas contemporâneas, a política se tornou gradativamente mais profissionalizada e mais distante da esfera civil, que passou a se preocupar menos com a vida pública e mais com seus próprios afazeres e vontades. Nas últimas décadas, entretanto, a lacuna entre representantes e representados se tornou tamanha que estes estão se sentindo cada vez mais apáticos e cínicos em relação àqueles e, também, em relação a instituições e atividades políticas. Nesse cenário, as tecnologias digitais aparecem como uma possível solução (ou, ao menos, alívio) para tal diagnóstico (Ward e Lusoli, 2005; Williamson, 2009a, 2009b).

Grosso modo, a interação entre agentes da esfera civil e da esfera política formal poderia acarretar uma série de impactos positivos na qualidade da democracia, tais como o esclarecimento de questões dos cidadãos, o registro de atitudes e inclinações políticas do público e mesmo a discussão e a construção colaborativa de ideias e projetos com a participação de representantes e representados. Assim, de uma maneira geral, estava muito presente na literatura mais recente o argumento de que as tecnologias digitais reduziriam o gap entre esfera civil e esfera política, e que essa redução aumentaria a confiança dos cidadãos em agentes e instituições políticas (ver Aggio, 2015; Kaid e Postelnicu, 2005; Stromer-Galley, 2014; Lilleker e Jackson, 2009).

Mesmo que não se aceite inteiramente a premissa acima apresentada, é fato que há uma expectativa na esfera civil de maior interatividade com seus representantes e instituições políticas, uma vez que já estamos interagindo online constantemente não apenas com outros indivíduos, mas com uma série de instituições do mercado, como bancos, agências de viagens e mesmo perfis de marcas (Coleman e Brumler, 2009). Isso, claro, também significa que a interatividade não pode se restringir àquela midiática ou àquela que ocorre de forma espontânea nas redes sociais digitais (tais como curtidas e compartilhamentos de postagens) e que se esperam respostas significativas após demandas de interação.

Portanto, compreendendo a resposta (ou feedback) como uma das formas de interação e como parte do processo de responsividade do representante para com o representado e o cidadão comum em geral (embora, evidentemente, esse processo não se limite a esse aspecto), o objetivo inicial deste artigo é verificar, primeiro, se os políticos brasileiros respondem aos questionamentos de seus eleitores e dos cidadãos em geral por intermédio das ferramentas propiciadas pela internet, e segundo, se existem incentivos ou fatores específicos que aumentam as chances de políticos responderem a essas 
demandas 4 . As questões de pesquisa foram elaboradas a partir de três discussões teóricas existentes na literatura e aprofundadas mais adiante. Essas questões são: a) o conteúdo das mensagens enviadas pelos cidadãos e potenciais eleitores influi na responsividade digital do representante? Com efeito, experimentos efetuados em outros países observam que, conforme o conteúdo da mensagem enviada ao membro do parlamento, a taxa de resposta pode ser uma ou outra, com mensagens que tratam de questões eleitorais apresentando uma taxa de resposta maior que mensagens sobre outros assuntos; b) existem incentivos de ordem distinta para que os políticos em geral (e os representantes em particular) interajam com os cidadãos em períodos eleitorais e não eleitorais (adiante podemos ver que, para um grupo de autores, essa diferença existe, enquanto outro a nega); e, por fim, c) as características da ferramenta digital utilizada (especialmente o email oficial disponibilizado e o inbox do Facebook) interferem na intensidade da interação com o representante? Para uma vertente da literatura, os e-mails, por seus atributos enquanto ferramenta de comunicação, se prestam menos a uma interação mais individualizada com o representante do que o Facebook, o qual dificulta o anonimato, o envio de spams e o overload ou sobrecarga de mensagens, especialmente as enviadas através de robôs ou bots, servindo assim como incentivo para um contato mais direto e informal entre cidadãos comuns e representantes. Dessa forma, o Facebook, por suas características enquanto mídia, serviria como uma plataforma mais eficaz de interação direta dos cidadãos com os políticos, que utilizam tanto as timelines das fanpages desses últimos quanto outros recursos, como o inbox através do aplicativo Messenger e mesmo endereços eletrônicos disponibilizados na plataforma.

Para descobrir as respostas a essas questões, realizamos um experimento, dividido em quatro rodadas, ao longo de um ano e meio de aplicações. Este artigo apresenta os resultados finais de tal experimento. Compusemos e enviamos mensagens, a partir de remetentes fictícios, via e-mail e mídias sociais, aos 513 deputados federais brasileiros, controlando, a cada etapa da aplicação, vários fatores, que depois testamos estatisticamente para identificar em que medida influenciam a probabilidade de os representantes responderem ou não. Ao todo, foram realizados 2.052 contatos, entre setembro de 2014 e julho de 2015, contemplando, portanto, as 54a e 55a legislaturas da Câmara dos Deputados do Brasil.

\footnotetext{
4 Em seu trabalho sobre os legislativos subnacionais dos EUA, Ferber e seus colaboradores propõem um "modelo de ciberinteratividade em seis dimensões", baseado nos seguintes níveis de interação propiciados pelas tecnologias digitais: (i) monólogo, em que há envio de comunicação somente de um lado; (ii) feedback, em que há comunicação de uma via com possibilidade de resposta do receptor; (iii) diálogo responsivo, em que há capacidade de resposta do destinatário, mas com elevado grau de controle do emissor; (iv) resposta controlada, em que as mensagens são publicizadas, mas com elevado grau de controle do emissor; ( $v$ ) discurso mútuo, em que há trocas públicas de mensagens sem início de processo deliberativo; (vi) debate público/deliberação, em que há trocas de ideias nas mensagens publicizadas com baixo grau de controle do emissor. Para os autores, cada um desses níveis de interação está associado a uma etapa do uso das tecnologias digitais e a determinada cultura política predominante entre os usuários das mídias digitais (cf. Ferber, Foltz e Pugliese, 2007; Perna e Braga, 2012). Em nosso experimento, nos concentramos no segundo nível de interatividade, que é o do feedback ou responsividade do parlamentar às interpelações dos cidadãos e potenciais eleitores.
} 
O primeiro modelo compara o conteúdo da mensagem enviada. O segundo modelo compara os períodos eleitoral e não eleitoral. O terceiro e último modelo compara a plataforma utilizada para contato. Testamos, portanto, três incentivos: a) o conteúdo efetivo da mensagem (uma eleitora oferecendo apoio eleitoral ao lado de outra cobrando um posicionamento sobre uma votação no plenário); b) o período temporal em que a mensagem foi enviada (eleitoral e não eleitoral); c) o meio pelo qual a mensagem foi enviada (e-mail e inbox do Facebook). Essas são nossas variáveis independentes, que testamos em um modelo de regressão logística. Complementarmente, para complexificar a análise, testamos também a influência de 15 variáveis, relacionadas a perfil, desempenho e atuação política dos parlamentares, como intervenientes, a fim de mensurar se haveria mudanças no efeito de nossas variáveis principais de acordo com os diferentes subgrupos de deputados e deputadas. Explicamos os detalhes dessas variáveis de controle adiante.

Esclareça-se desde o início que o objetivo central de nosso artigo não é testar o potencial das redes digitais como um todo para aumentar a interação dos representantes com os cidadãos por meio da internet - esse potencial já tem sido objeto de inúmeros estudos no Brasil e em outros países -, mas sim relatar os resultados de um experimento avaliando uma dimensão específica dessa interatividade, qual seja, aquela que ocorre por meio de e-mails e mensagens internas no Facebook. Assim sendo, o experimento não deve ser utilizado como um meio exclusivo ou mesmo predominante para avaliar o potencial de interação do Facebook, o qual pode ser auferido complementarmente por outras métricas, como, por exemplo, o engajamento e o impacto das mensagens divulgadas pelos representantes.

Feitos esses esclarecimentos preliminares, nossas hipóteses são as seguintes:

Hipótese 1: Políticos tendem a responder mais a mensagens que possuam, em seu conteúdo, incentivos eleitorais do que a mensagens sobre temas intrusivos, com aspectos técnicos e/ou sem incentivos eleitorais.

Hipótese 2: Políticos tendem a responder mais a mensagens em períodos eleitorais do que em períodos não eleitorais.

Hipótese 3: Políticos tendem a responder mais mensagens enviadas por meio de novas plataformas de comunicação (mídias sociais) do que por meios tradicionais (e-mail).

Hipótese 4: Colocados sob a mesma estrutura de incentivos, atores racionais, mesmo que com distintos perfis sociais e políticos, tendem a reagir de forma semelhante.

O artigo se organiza da seguinte maneira: além da Introdução e das Considerações finais, na primeira seção, "Responsividade e incentivos", realizamos uma revisão de literatura e apresentamos alguns parâmetros analíticos que justificam o experimento sobre a responsividade dos políticos por intermédio das ferramentas digitais. Argumentamos que, embora a questão seja relativamente simples, ela é um indicador do processo de responsividade, que, por sua vez, é um dos pilares da democracia representativa moderna (Mansbridge, 2003; Manin, 2013). Também apresentamos na segunda seção, "Experimentos e comportamento político", estudos internacionais que já realizaram 
experimentos semelhantes, conduzidos nos Estados Unidos e na Europa, nos quais esta pesquisa é inspirada, além de alguns poucos estudos de natureza análoga existentes no Brasil. Na seção seguinte, "Desenho de pesquisa", são apresentados os contornos mais gerais de nossa análise, momento no qual também são tratadas as questões éticas envolvendo o experimento. A seguir, nas seções "Resultados" e "Discussão", são apresentados e debatidos os resultados da pesquisa, cotejando-os à luz da literatura. Eles apontam que, surpreendentemente, o período eleitoral não exerce grande influência na probabilidade de obter uma resposta. Por outro lado, os incentivos do conteúdo presentes na mensagem, assim como o meio pelo qual ela foi enviada, apresentam valores estatisticamente fortes. Apontamos duas ordens distintas de argumentos para explicar isso. Sobre os incentivos de conteúdo, nos baseamos nas teorias clássicas sobre comportamento político. Sobre as redes sociais, além da própria ascensão desse meio de comunicação, apontamos aspectos organizacionais dos gabinetes legislativos e as características de cada mídia digital como possíveis explicações para a razão de essa plataforma se constituir em um meio privilegiado de comunicação entre eleitores e representantes.

\section{Responsividade e incentivos}

Se representar significa ser responsivo aos representados (Pitkin, 1967), a accountability é "o mais fundamental requerimento da governança democrática" (Coleman, 2005, p. 190 $)^{5}$. Dessa perspectiva, estar ao alcance dos eleitores e responder a estes é fundamental. O princípio da accountability é simples, embora a teoria seja mais complexa do que isso: os representantes devem prestar contas e ser responsivos (accountable) perante aqueles que os incumbem de poder. Se não o fazem, estão suscetíveis a diversos mecanismos de sanção, que podem ocorrer por outras instituições do próprio Estado ou mesmo pela soberania popular, que pode promover uma sanção posterior, retirando-os do poder (Miguel, 2005). Mecanismos de accountability, portanto, se referem às formas como esta ocorre: o governante prestando contas e sendo responsivo ao cidadão (answerability) e as punições sendo realizadas por órgãos competentes (enforcement) e/ou por cidadãos durante o momento das eleições (electoral accountability) (Schedler, 1999). Muitos autores têm chamado a atenção para o fato de que o desenvolvimento das tecnologias digitais, cada vez mais interativas, tem promovido mudanças incrementais em direção a uma forma de comunicação mais direta com os cidadãos, colocando nas mãos do representante ferramentas para uma prestação de contas direta e quase em tempo real de suas atividades (Coleman, 2005; Coleman e Moss, 2008). Esse fenômeno pode relacionar-se com o princípio da accountability na medida em que um parlamentar pouco responsivo (ou seja, que não responde aos questionamentos e demandas dos cidadãos, ou

\footnotetext{
5 No original: "accountability of representatives to the represented is the most fundamental requirement of democratic governance".
} 
que prevarica, durante o exercício do mandato) está sujeito a sanções por ocasião das eleições, isto é, pode não ser reeleito justamente em função dessa frustração das expectativas de sua base eleitoral originária e dos cidadãos de uma maneira geral.

Estudos já desenvolvidos nessa seara versam sobre questões significativamente distintas, como o papel das instituições políticas na modulação das estruturas de accountability (Lederman, Loayza e Soares, 2005), a relação entre centralização e descentralização do governo e accountability (Seabright, 1996), o processo de decisionmaking no parlamento (Bergman et al., 2006), a importância dos partidos políticos como mediadores para a accountability (Müller, 2000), a relação entre accountability e cobertura da imprensa (Snyder Jr. e Strömberg, 2010), a relação entre eleitores, accountability e patrimonialismo (Lyne, 2007), além de experimentos que testam se o eleitor olha retrospectivamente para demandar accountability de seus representantes durante os pleitos (Woon, 2012) ou se os parlamentares respondem às demandas recebidas e as encaminham (Broockman, 2013).

Na contemporaneidade, se um dos desafios da interação, da participação e da responsividade envolvendo agentes políticos e cidadãos está na questão da escala (i.e., a impossibilidade de formas de interação e participação direta dos cidadãos por restrições temporais e geográficas), certamente os novos meios digitais e online parecem oferecer oportunidades para aumentar a responsividade dos representantes aos representados através de oferta de uma miríade de mecanismos digitais de interação (Coleman, 2005; Coleman e Brumler, 2009; Marques, 2007), como é o caso de plataformas e aplicativos de redes sociais, wikis, blogs ou mesmo através de mecanismos diretos, como formulários de contato e e-mail, geralmente disponíveis em websites de representantes e instituições. Em outras palavras, tornou-se tarefa hercúlea (se não impraticável) para os representantes políticos responderem pessoalmente às demandas de seus representados de forma direta e constante.

Segundo Manin (1995), com a evolução das formas de representação, a tarefa de intermediação entre cidadãos e governo passou, inicialmente, para os partidos políticos, que recebiam e reenviavam dúvidas e demandas cidadãs, e, posteriormente, para a imprensa, que passou a controlar o que Gomes (2004) chama de esfera de visibilidade pública. Ou seja, em grande medida, nas sociedades contemporâneas, os cidadãos só têm suas demandas ouvidas e respondidas se conseguirem, anteriormente, atrair cobertura jornalística e, consequentemente, visibilidade midiática para suas requisições.

Atualmente as redes digitais oferecem ferramentas online que permitem, potencialmente, que essa interação aconteça de maneira mais rápida, direta ${ }^{6}$ e frequente. A título de exemplo, podemos entender os websites de candidatos e governos como portais de informação e de resposta a diversas demandas de accountability (enquanto answerability) da sociedade (Marques, 2007; Silva, 2005). Se antes o mais comum era o

\footnotetext{
6 Sem, por exemplo, a mediação realizada por partidos políticos ou mesmo pela indústria da informação, nomeadamente, o jornalismo (cf. Coleman, 2005).
} 
envio de cartas a seu representante, tal processo se tornou consideravelmente mais fácil e rápido com os recursos da internet e formas de comunicação online. Agora, por exemplo, um mesmo e-mail pode seguir velozmente para vários parlamentares (ou mesmo para todos!), especialmente quando o desejo é fazer pressão sobre eles (Pereira, Marona e Pinheiro, 2011; Stábile, 2012).

Nos tempos atuais, tentamos interagir e esperamos algum tipo de resposta de nossos candidatos e atores políticos nas mídias sociais (e.g., Twitter, Facebook, Instagram etc.), uma vez que a interação é uma das características mais marcantes dessas plataformas e se espera que os agentes políticos moldem seus comportamentos de acordo com esses meios (Aggio, 2015; Braga, Nicolás e Becher, 2013; Chadwick, 2009; Coleman, 2005; Marques e Sampaio, 2011).

Desde há algum tempo, estudos têm apontado que isso implica vários ganhos para os parlamentares em capacidade de comunicação e divulgação de mensagens, mas também alguns custos e problemas, tais como a ausência de staff ou capacidade técnica para lidar com as novas ferramentas de comunicação, o excesso de mensagens por parte dos internautas ou mesmo o desinteresse puro e simples de lidar com as novas ferramentas digitais (Alperin e Schultz, 2003; Ward e Lusoli, 2005). A referência clássica aqui é o trabalho de Stromer-Galley (2000), que aponta três razões básicas para que os candidatos evitem a interação com os cidadãos, especialmente em períodos eleitorais: onerosidade, riscos da perda de controle pelo emissor e perda da ambiguidade do discurso. Entretanto, se isso era válido para os tempos da primeira geração das ferramentas da internet, estudos recentes afirmam que, com a sofisticação das tecnologias digitais e sua entrada num segundo estágio mais colaborativo, essas possibilidades de interação aumentam e, por conseguinte, também as possibilidades de uma responsividade mais direta do representante em relação aos cidadãos (Aggio, 2015; Coleman, 2005; Gibson, 2015).

Entendemos que o e-mail continua sendo uma forma mais "oficial" de contato que as páginas de redes sociais, podendo assim receber um tratamento diferenciado pelos parlamentares. A título de exemplo, no portal da Câmara, no contato de cada deputado, há geralmente números de telefone de seu gabinete e seu endereço oficial de e-mail (e não o de suas páginas nas redes sociais).

Não obstante, reconhece-se que os deputados podem ser resistentes em responder e-mails por uma gama de fatores. Evidentemente, o principal motivo tende a ser a excessiva quantidade de mensagens (Marques, 2007). Para além de todos os cidadãos e grupos interessados em tirar suas dúvidas ou enviar demandas aos parlamentares, não podemos ignorar que, atualmente, um considerável conjunto de atores enviam constantemente e-mails a vários deputados para fazer pressão sobre determinadas votações. Além dos grupos de pressão tradicionais, também estamos nos referindo a grupos de pressão sem presença física, como é o caso do Avaaz (Aldé e Santos, 2012), que realizam petições online e enviam e-mails aos parlamentares em nome de seus participantes, utilizando ferramentas que são criadas para enviar automaticamente e-mails 
a todos os parlamentares sobre determinada questão, como foi o caso, por exemplo, do impeachment da ex-presidente Dilma Rousseff ${ }^{7}$.

Entretanto, os estudos demonstram que, apesar dos novos canais e meios digitais, a interação básica entre representantes e representados é, constantemente, relegada. Vaccari (2014) abordou o tema dos e-mails dos candidatos e partidos, comparando seis países europeus e Estados Unidos, em artigo ironicamente intitulado "Você não recebeu nenhum e-mail". Para o autor, a importância do objeto reside no fato de ser esse um componente básico da comunicação online dos internautas, tendo baixo custo para o usuário, sem que este precise estabelecer relações pessoais com os gabinetes. Vaccari afirma a importância do objeto:

Although email is still one of the most popular components of users' experience of the internet, its use by political actors in campaigns has rarely been studied. Because it is easy to use and a constant presence in citizens' everyday digital lives, email can be an important communication channel between elites and voters in representative democracy. Email can allow citizens to send feedback to politicians at very little cost and without the need to establish personal connections with often distant and inaccessible staffers (Vaccari, 2012, p. 1).

Portanto, podemos tomar, tal qual Vaccari, esse objeto como um indicador (proxy) de responsividade dos representantes - sem que, novamente relembramos, isso implique reduzir o conceito a somente essa ação.

No Brasil, foram efetuados poucos estudos sobre a responsividade dos parlamentares através de e-mails e outras ferramentas digitais. Os estudos pioneiros de França, Martins e Braga encontraram uma baixa taxa de resposta dos vereadores, deputados estaduais e federais, tendo os vereadores maior responsividade que estas duas últimas categorias de representantes (França, Martins e Braga, 2006). Martins também encontrou uma baixa taxa de resposta em sua análise da tramitação da lei de biossegurança (Martins, 2005) e Pereira, Marona e Pinheiro (2011), em sua análise do programa "Fale com o Deputado", da Câmara do Deputados, encontraram taxa de resposta média de cerca de 5,0\% nos e-mails enviados aos parlamentares. Entretanto, inexistem ainda estudos sistemáticos sobre se novas ferramentas digitais como o Facebook estão ou não alterando esse tipo de comunicação mais direta entre representantes e cidadãos, sendo este um dos motivos que justificam a realização deste estudo experimental. Como sabemos, o Facebook é uma plataforma catch-all, ou seja, que busca trazer para si o máximo possível de formas de interação. Portanto, há perfis públicos, páginas pessoais, grupos de usuários e mesmo o chat individual. Cada uma delas tem suas especificidades

\footnotetext{
7 O "Mapa da Democracia" (<http://www.mapadademocracia.org.br/>), por exemplo, enviava mensagens aos parlamentares indecisos para que votassem contra o impeachment da presidente Dilma Rousseff. Enquanto o "Mapa do Impeachment" fazia justamente o contrário, pressionando a favor do impeachment (<http://mapa.vemprarua.net/>). Acesso em: 9 jan. 2017.
} 
em termos de affordances e possibilidades de interação ${ }^{8}$. Para o experimento, foi utilizada justamente a ferramenta de interação individual direta (chat) com o perfil público de cada deputado. Acreditamos que seja aquela que justamente mais se aproxima do e-mail.

\section{Experimentos e comportamento político}

O método experimental está em ascensão e tem se tornado, no âmbito internacional, uma abordagem em crescente expansão (Mullinix et al., 2015). Experimentos se caracterizam, basicamente, por controle e manipulação intencional de fatores de tratamento, que permitem identificar fatores causais no comportamento observado dos objetos em análise. Embora seja ainda pouco frequente na ciência política brasileira (Zucco Jr., 2013), a abordagem pode servir a diversos propósitos, como mostram estudos recentes de Turgeon e Rennó (2010) e Vidigal (2015).

Podemos distinguir dois tipos principais de experimentos realizados na ciência política: com eleitores e com elites políticas. O primeiro tipo é muito mais comum, sobretudo nos Estados Unidos, relacionado aos incentivos para comparecimento eleitoral. O segundo tipo está em ascensão nos anos recentes (Loewen, Rubenson e Wantchekon, 2010).

Nosso desenho de pesquisa foi baseado, inicialmente, nos experimentos de Broockman (2013) e Vaccari (2014), abordados adiante, mas também encontra proximidade com os de Spada e Guimarães (2013). Algumas das variáveis que utilizamos aqui, contudo, estão presentes há muito tempo em estudos correlatos.

O experimento de Broockman (2013) que tomamos por ponto de partida testou, nos Estados Unidos, as chances de congressistas brancos e negros responderem a uma demanda vinda de um cidadão negro. O autor enviou cartas aos congressistas de um remetente fictício, pedindo ajuda com benefícios de desemprego. Quando o remetente se identificava como sendo do mesmo distrito eleitoral do congressista, não houve diferença estatística entre deputados brancos e negros, apontando que os incentivos eleitorais (expectativa de ganhar votos futuros) levam congressistas brancos a responder e ajudar eleitores negros. Mas, quando o remetente era de fora do distrito (ou seja, não havia incentivos eleitorais), a taxa de respostas dos congressistas negros foi substancialmente maior. O autor atribui isso ao que chama de motivações intrínsecas, próprias do indivíduo. Sua conclusão é de que políticos possuem maior tendência a promover os interesses daqueles com quem compartilham caraterísticas pessoais, tais como sexo, raça, profissão, classe ou orientação sexual. Essas motivações intrínsecas, contudo, estão fora de nosso escopo.

A pesquisa de Broockman (2013) foi reproduzida por McClendon (2016) na África do Sul. A taxa média de respostas obtidas foi de apenas 12,9\%, levando a autora a sugerir

\footnotetext{
8 Como já frisado, não encontramos experimentos semelhantes ao nosso, mas o uso do Facebook em momentos eleitorais (ver Cervi, Massuchin, Carvalho, 2016) ou mesmo em conversações políticas (Carreiro, 2017) já tem recebido atenção da academia brasileira.
} 
que, apesar das distinções raciais, que são o foco de sua discussão, em geral, os políticos não são responsivos a ninguém. Adiante vemos que esse dado pode ser cotejado com nossos resultados.

Já Vaccari (2014) conduziu experimento em que buscou saber se o conteúdo da mensagem influenciava a taxa de respostas de candidatos. Para isso, mandou e-mails fictícios a estes, durante eleições de seis países europeus, além dos Estados Unidos. Em um e-mail, o remetente perguntava informações sobre uma questão de política pública, em outro, oferecia-se como voluntário de sua campanha. Para surpresa do autor, não houve grandes diferenças estatísticas entre as respostas obtidas para cada um dos e-mails, o que leva Vaccari a concluir que os candidatos não dão atenção a essa ferramenta de comunicação como parte da campanha ou do recrutamento de eleitores. Nesse experimento, o autor controlou apenas o conteúdo da mensagem, durante o período eleitoral, assim como fazemos na primeira etapa de nossa pesquisa.

O conteúdo da mensagem, testado por Vaccari (2014), é uma das variáveis mais utilizadas em experimentos eleitorais. Cardy (2005) e Panagopoulos (2009) compararam conteúdos de mensagens partidárias e não partidárias na convocação para votar, não encontrando diferenças substanciais - o que sugeria que outros fatores, como interesse em política, seriam mais importantes do que o conteúdo das mensagens. Gerber, Green e Green (2003) apontaram que tanto o conteúdo quanto o número de cartas enviadas convocando para a votação podiam ter efeito negativo no comparecimento eleitoral. No recorte sobre recrutamento de elites políticas, com foco na questão de gênero, Preece e Stoddard (2015) descobriram que mensagens específicas, explicitando incentivos para candidatas, tendiam a suscitar maior interesse do grupo feminino. Fora do período eleitoral, Butler, Karpowitz e Pope (2012) investigaram se os parlamentares tendiam a responder a mais demandas sobre políticas públicas ou solicitações de serviços, descobrindo que, tanto no nível estadual quanto federal (Estados Unidos), deputados tendem a ser mais responsivos a pedidos de serviços do que a policies. Já Spada e Guimarães (2013) testaram se candidatos, durante o período eleitoral, são mais responsivos a eleitores identificados como "fiéis" ou a indecisos, comparando, como placebo, e-mails sem referência a eleições. Os autores descobriram que candidatos tendem a responder indiscriminadamente a potenciais eleitores - comparativamente aos sem identificação - sejam indecisos ou fiéis.

No caso do Brasil, exceto por Spada e Guimarães (2013), não temos uma tradição de experimentos controlados como este aqui proposto, porém, em alguns estudos (Marques, 2007; Marques e Miola, 2007), chegou-se a verificar as formas de contato com websites do Congresso e mesmo a enviar e-mails aos membros do Congresso. Em um caso análogo, Silva (2005) também testou o envio de e-mails para todas as capitais brasileiras. Temos, então, também a importância das plataformas de comunicação em si como uma variável que pode intervir, positiva ou negativamente, no comportamento desses atores e na relação possível entre eleitor e representante. 
É isso que nosso terceiro modelo irá testar: os meios pelos quais os parlamentares foram contatados. Uma abordagem próxima a esta é o experimento de Gerber e Green (2000) em New Haven, comparando diversos meios de comunicação utilizados para incentivar o comparecimento eleitoral. Seus resultados apontaram que o contato pessoal aumentava substancialmente o comparecimento, a correspondência tinha um efeito baixo e os telefonemas não tinham efeito algum. Alperin e Schultz (2003) realizaram experimento em que visava testar a eficácia das respostas de parlamentares de dois estados dos Estados Unidos em distintos tipos de contato (por carta, fax, telefone etc.). Esse desenho de pesquisa se aproxima daquele que aqui adotamos, em relação à última de nossas variáveis independentes.

\section{Desenho de pesquisa}

Nosso objetivo neste artigo é identificar em que medida certos incentivos, que controlamos, podem ou não explicar a assimetria sobre quão responsivos são os parlamentares nas mídias digitais. O universo tratado se refere aos deputados no exercício do cargo, no momento de cada aplicação, conforme informações divulgadas no site da Câmara dos Deputados. Releve-se que tratamos apenas de uma dimensão da responsividade dos deputados, qual seja, os feedbacks a mensagens especificamente endereçadas pelos eleitores aos parlamentares através de contatos individualizados como e-mails e mensagens pessoais no Facebook. Não analisamos aqui outros tipos de responsividade dos políticos aos cidadãos, tais como a interação dos deputados ou de sua assessoria a mensagens postadas pelos eleitores na timeline de sua fanpage, entre outras formas e instâncias de accountability existentes.

O Quadro 1 sintetiza as características das mensagens enviadas. O conteúdo completo das mensagens está no Anexo: 
Quadro 1

Síntese das caraterísticas das mensagens enviadas

\begin{tabular}{|c|c|c|c|c|c|}
\hline Mensagem & Meio & Data & Período & Tema & Características da mensagem \\
\hline 1 & E-mail & Setembro de 2014 & Eleitoral & $\begin{array}{l}\text { Apoio } \\
\text { eleitoral }\end{array}$ & $\begin{array}{l}\text { - Eleitora anterior, suscetível a } \\
\text { mudança de opinião (votou por } \\
\text { sugestão de terceiro), e tendendo } \\
\text { a votar novamente. } \\
\text { - Reconhece não acompanhar } \\
\text { política e que a ideia do contato } \\
\text { sequer foi dela (indica estar } \\
\text { aberta a qualquer resposta). } \\
\text { - Pergunta genérica sobre o que } \\
\text { o/a representante fez durante o } \\
\text { mandato. }\end{array}$ \\
\hline 2 & E-mail & Setembro de 2014 & Eleitoral & Pré-Sal & $\begin{array}{l}\text { - Sem apresentação do emissor. } \\
\text { - Pergunta objetiva sobre o } \\
\text { posicionamento do/a deputado/a } \\
\text { em relação ao tema votado no } \\
\text { plenário. } \\
\text { - Emissor se mostra } \\
\text { razoavelmente informado (leu } \\
\text { sobre o debate). } \\
\text { - Tema que envolve um debate } \\
\text { com argumentos técnicos, bem } \\
\text { específico. } \\
\end{array}$ \\
\hline 3 & E-mail & Junho de 2015 & $\begin{array}{c}\text { Não } \\
\text { eleitoral }\end{array}$ & $\begin{array}{l}\text { Reforma } \\
\text { política }\end{array}$ & $\begin{array}{l}\text { - Eleitora anterior, que não } \\
\text { acompanha política. } \\
\text { - Pergunta ampla sobre um tema } \\
\text { específico. } \\
\text { - Não apresenta posicionamento } \\
\text { pessoal, de modo que não } \\
\text { constrange o/a deputado/a a não } \\
\text { responder, caso as opiniões } \\
\text { fossem conflitantes. } \\
\end{array}$ \\
\hline 4 & $\begin{array}{c}\text { Facebook } \\
\text { (inbox) }\end{array}$ & Julho de 2015 & $\begin{array}{c}\text { Não } \\
\text { eleitoral }\end{array}$ & $\begin{array}{c}\text { Maioridade } \\
\text { penal }\end{array}$ & $\begin{array}{l}\text { - Sem apresentação pessoal do } \\
\text { emissor. } \\
\text { - Pergunta ampla, mas sobre um } \\
\text { tema objetivo, votado em } \\
\text { plenário. } \\
\text { - Não apresenta posicionamento } \\
\text { pessoal. }\end{array}$ \\
\hline
\end{tabular}

Fonte: Elaboração própria a partir da base de dados do projeto: "Elites políticas e tecnologias digitais de uma perspectiva comparada".

Nosso objetivo não foi entrar no conteúdo substantivo das respostas, apenas verificar se foram ou não respondidas as mensagens. Isto é, se os gabinetes respondem ou não às questões, e não como respondem .

9 Embora a quase totalidade atenda a critérios básicos de satisfação de resposta, vale notar, a título de curiosidade, poucas exceções cuja resposta foi insuficiente. Por exemplo, uma assessoria informou que a PEC sobre redução da maioridade penal havia sido aprovada e, então, iria para o Senado e depois para sanção presidencial. Trata-se de um erro fatual sobre o processo legislativo, uma vez que emendas constitucionais são promulgadas diretamente pelo Congresso Nacional, sem passar por sanção ou veto presidencial. 
Vale pontuar que, em termos metodológicos, algumas das preocupações técnicas desta pesquisa são distintas das pesquisas debatidas na seção anterior. Uma vez que experimentos com elites políticas limitem seu escopo aos eleitos (como é nosso caso), o universo inteiro é atingido. Dessa forma, questões como amostragem não se aplicam. Esse é o tipo de pesquisa que Couper (2000) chamou de "amostra baseada em listas", sendo probabilística. Em termos comparativos, essa é uma vantagem imensa em relação a experimentos com eleitores ou outros recortes, como o conjunto total dos candidatos não eleitos.

Os casos escolhidos para serem tema dos questionamentos foram votações que ocorreram nominalmente no plenário. Como existem temas que são votados por liderança partidária, se fizéssemos perguntas sobre esses votos, hipoteticamente os deputados poderiam não responder, caso não quisessem publicizar suas opiniões pessoais. Uma vez que tratamos de votações nominais, não há motivos para não querer divulgar suas posições, já que seus votos são públicos e encontram-se no site da Câmara dos Deputados e na imprensa em geral.

A segmentação dos casos também foi planejada a fim de, mantendo a comparabilidade entre as variáveis que desejávamos comparar, maximizar os resultados. No caso do último modelo (que visa comparar o meio de comunicação), nosso objetivo central era cotejar a resposta por mídia social (Facebook) com uma ferramenta mais tradicional (e-mail). Dessa forma, optamos por não segmentar os conteúdos das mensagens enviadas por aquela via, já que isso é desnecessário para a comparação objetivada. Acreditamos que a parcimônia no desenho de pesquisa é uma de suas vantagens.

Adicionalmente, após testarmos as três variáveis que compõem o centro desta pesquisa, optamos por colocar à prova a força delas, testando seus efeitos com 15 variáveis intervenientes, sobre perfil social e político dos parlamentares. Seria razoável alguém supor que os incentivos que testamos talvez não afetem todo o conjunto de parlamentares da mesma forma. Isto é, indivíduos poderiam reagir de forma distinta aos incentivos que Ihes são impingidos, de acordo com sua filiação partidária, background educacional, faixa etária, e assim por diante. Ainda que todos estejam, de fato, sob o mesmo conjunto de regras do sistema democrático e da Câmara dos Deputados brasileira, eles também detêm e se filiam a uma série de outros marcadores sociais, de nível individual, que podem influenciar seu comportamento. Embora tal argumento seja válido - e o testamos -, tomamos por hipótese a negativa de tal argumento, como apresentado na Introdução, por uma questão de coerência lógica com o arcabouço teórico que adotamos. Apresentamos a lista das variáveis utilizadas na próxima seção no momento de realização do teste. Importante notar que essas variáveis são utilizadas como intervenientes, não como variáveis explicativas. Isto é, vamos verificar se, colocadas como covariantes, interferem no modo como as três variáveis explicativas - objeto de nosso artigo - comportam-se. Para isso, utilizamos a análise de covariância (Ancova), que identifica se existe variação intragrupo. 


\section{Questões éticas}

Experiências com seres humanos demandam que tratemos dos aspectos éticos relativos a sua manipulação. Como descrevemos na seção "Resposividade e incentivos", nosso estudo segue o mesmo procedimento utilizado no experimento de Vaccari (2014) em seis países europeus e Estados Unidos. Além de Vaccari, esse desenho de pesquisa também foi aplicado por Broockman (2013), entre diversos outros estudos com procedimentos semelhantes. A manipulação, no caso, não ocorreu em termos que pudesse influir em qualquer conduta dos outputs desses gabinetes - como está, no limite, em Broockman (2013), o que implicaria questões muito mais delicadas - mas tão somente nos insumos providos para verificar quando respondiam ou não aos cidadãos.

As respostas demandadas aos parlamentares exigiam o mínimo de tempo possível para ser redigida, de modo que não houve prejuízo potencial para o serviço público do trabalho dos gabinetes.

Nenhum nome dos deputados que responderam ou deixaram de responder foi ou será divulgado. Todas as identidades estão sob sigilo. O objetivo não é fazer avaliações individuais, mas verificar as tendências gerais do comportamento político dos gabinetes parlamentares na questão em estudo, identificando possíveis determinantes para tais tendências.

Isso posto, não há maiores questões éticas envolvendo o experimento.

\section{Resultados}

Como já explicamos, o objetivo deste artigo é controlar os incentivos dados aos deputados federais nas mensagens recebidas de hipotéticos cidadãos, a fim de verificar possíveis influências sobre a probabilidade de responderem ou não aos questionamentos enviados.

Temos, portanto, três modelos distintos, que comparam os parâmetros propostos, a fim de isolar os possíveis efeitos. O primeiro modelo compara somente o conteúdo das mensagens 1 e 2 . O segundo modelo se propõe a comparar os períodos das mensagens e apresenta duas variações: a primeira compara a mensagem 3 (não eleitoral) com a 1 (eleitoral, com incentivos para resposta); a segunda compara a mensagem 3 com a 2 (eleitoral, mas sem incentivos). O terceiro modelo compara as mensagens 3 e 4, enviadas no mesmo período (não eleitoral), por plataformas distintas (e-mail e Facebook).

Primeiramente, vamos apresentar nos Gráficos 1, 2 e 3 as taxas de respostas simples obtidas, para todos os cenários. Os casos de missing em e-mails se devem àqueles que retornaram ao remetente, acusando não terem sido entregues devido à caixa de emails estar lotada. No caso do Facebook, os missings se referem aos deputados que, no momento da aplicação do experimento, não possuíam página oficial nessa plataforma ou 
não permitiam o envio de mensagens privadas ${ }^{10}$. Esses dados são apresentados nesse momento a título de informação. Os cálculos dos testes apresentados posteriormente (diferença de médias e regressão) consideram apenas os valores válidos, como é o procedimento estatisticamente correto.

Gráfico 1

Porcentagem das respostas de acordo com os incentivos (com missing)

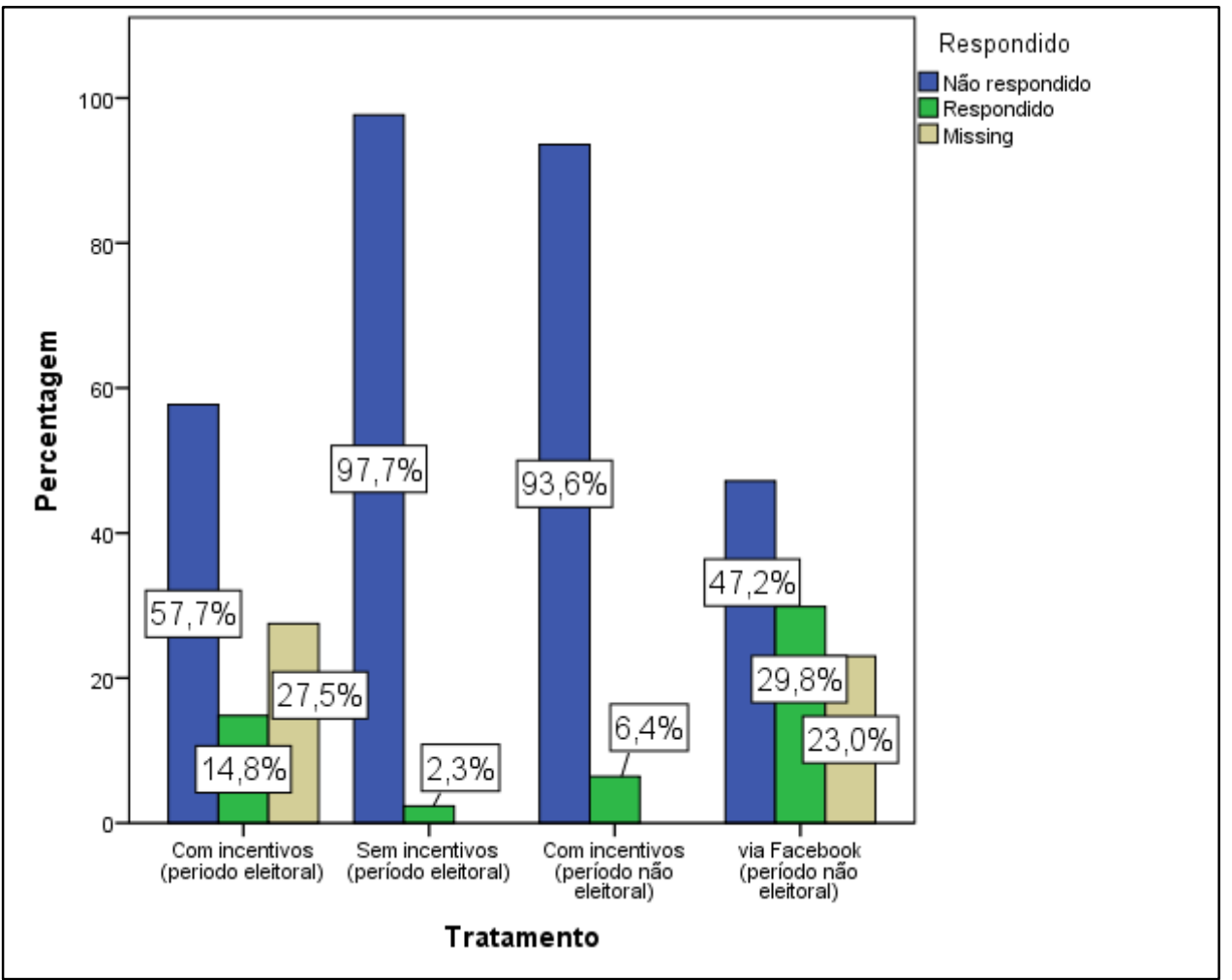

Fonte: Elaboração própria a partir da base de dados do projeto: "Elites políticas e tecnologias digitais de uma perspectiva comparada".

\footnotetext{
10 Uma característica do Facebook é que o usuário pode ter uma página, mas não autorizar que outros usuários lhe enviem mensagens privadas. Como essa foi a abordagem escolhida para contato, consideramos esses casos como ausentes.
} 
Gráfico 2

Porcentagem das respostas de acordo com os incentivos (sem missing)

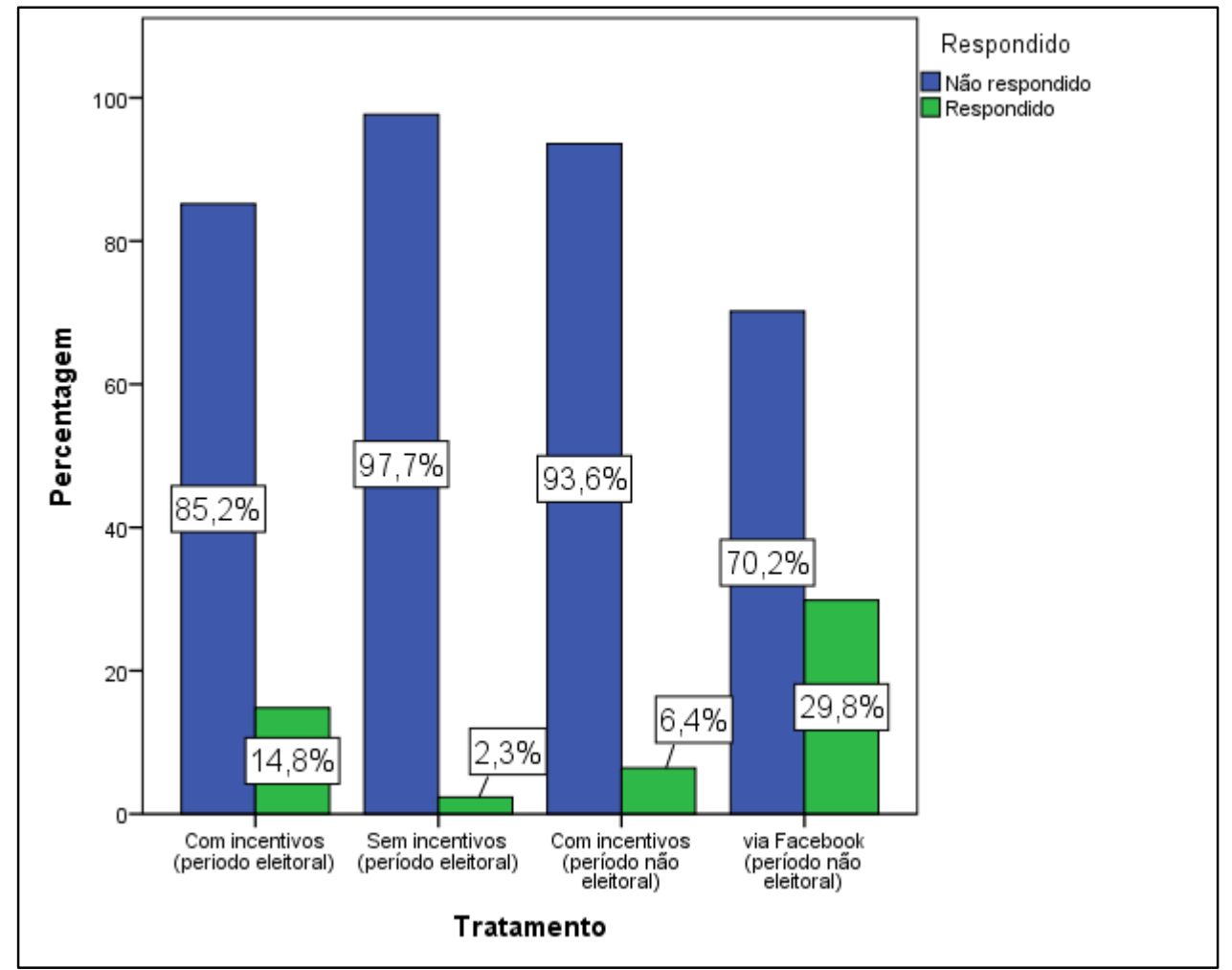

Fonte: Elaboração própria a partir da base de dados do projeto: "Elites políticas e tecnologias digitais de uma perspectiva comparada".

Podemos, desde já, verificar as distinções claras entre cada tipo de incentivo. As mensagens sem incentivos eleitorais geraram apenas 12 respostas, enquanto aquelas com incentivos eleitorais (mesmo que nessa categoria existam 141 missings) obtiveram 76 respostas. Ambos os tipos de mensagem em período eleitoral. Já no período não eleitoral, mesmo com incentivos, foram obtidas apenas 33 respostas. Já no Facebook, mesmo que apenas 395 representantes estivessem presentes na rede ou permitissem envio de mensagens privadas, foram obtidas 118 respostas.

As taxas de respostas dos parlamentares, em praticamente todos os momentos, são substancialmente baixas. Nos e-mails, variam de apenas 2,3\% a 14,8\% dos deputados federais. A taxa máxima de retorno obtida, via Facebook, chega a $29,8 \%$ do universo dos representantes. Acreditamos que podemos considerar isso, em termos gerais, como um indicador da reduzida "responsividade virtual" dos representantes junto aos seus constituents.

A seguir, o teste de Bonferroni para diferenças de médias averigua as diferenças estatísticas em quatro comparações. Como já explicado, o primeiro modelo calcula o email com incentivos em relação ao e-mail intrusivo (e-mails sem incentivos ou de conteúdo 
técnico), ambos no período eleitoral. A segunda e a terceira comparações testam os emails enviados no período eleitoral, com base nos e-mails enviados no período não eleitoral. A distinção é que a segunda comparação utiliza os e-mails com incentivos e a terceira os e-mails intrusivos. Enfim, por último, comparam-se as mensagens enviadas via Facebook em relação aos e-mails, ambos no mesmo período (não eleitoral).

Tabela 1

Teste de diferenças de médias

\begin{tabular}{|l|c|c|c|c|c|c|}
\hline Tratamento & Controle & $\begin{array}{c}\text { Diferença } \\
\text { média }\end{array}$ & $\begin{array}{c}\text { Desvio- } \\
\text { padrão }\end{array}$ & Significância & \multicolumn{2}{|c|}{$\begin{array}{c}\text { 95\% Intervalo } \\
\text { de confiança }\end{array}$} \\
\cline { 4 - 7 } & $\begin{array}{c}\text { Limite } \\
\text { interior }\end{array}$ & $\begin{array}{c}\text { Limite } \\
\text { superior }\end{array}$ \\
\hline $\begin{array}{l}\text { Com } \\
\text { incentivos } \\
\text { (período } \\
\text { eleitoral) }\end{array}$ & $\begin{array}{c}\text { incentivos } \\
\text { (período } \\
\text { eleitoral) }\end{array}$ &, $1809^{*}$ &, 0226 &, 000 &, 121 &, 241 \\
\hline $\begin{array}{l}\text { Período } \\
\text { eleitoral } \\
\text { (com } \\
\text { incentivos) }\end{array}$ & $\begin{array}{c}\text { Período não } \\
\text { eleitoral } \\
\text { (com } \\
\text { incentivos) }\end{array}$ &, $1400^{*}$ &, 0226 &, 000 &, 080 &, 200 \\
\hline $\begin{array}{l}\text { Período } \\
\text { eleitoral } \\
\text { (sem } \\
\text { incentivos) }\end{array}$ & $\begin{array}{c}\text { Período não } \\
\text { eleitoral } \\
\text { (com } \\
\text { incentivos) }\end{array}$ &,- 0409 &, 0207 &, 289 &,- 096 &, 014 \\
\hline $\begin{array}{l}\text { Via Facebook } \\
\text { (período não } \\
\text { eleitoral) }\end{array}$ & $\begin{array}{c}\text { via e-mail } \\
\text { (período } \\
\text { não } \\
\text { eleitoral) }\end{array}$ &, $3230^{*}$ &, 0222 &, 000 &, 264 &, 382 \\
\hline
\end{tabular}

Fonte: Elaboração própria a partir da base de dados do projeto: "Elites políticas e tecnologias digitais de uma perspectiva comparada".

* A diferença é significativa no nível 0,05.

Antes de mais, percebemos que a terceira comparação não tem validade, como indicado pelo intervalo de confiança e pelo $p$-value. Os incentivos da mensagem e o período eleitoral, nesse momento, se apresentam em patamares próximos. Mas a plataforma utilizada é a que apresenta os resultados mais elevados de diferença de médias, além de ser o único modelo em que o erro-padrão não ultrapassa a diferença de médias. Vamos comentar esses resultados de modo mais aprofundado adiante, à luz do próximo teste.

A seguir, realizamos uma regressão logística, apropriada para variáveis dependentes binárias, a fim de identificar as probabilidades de que um evento ocorra em relação a outro. Ou seja, qual porcentagem a mais de chances de obter uma resposta dos representantes cada tratamento implica? As bases de comparação utilizadas no teste são as mesmas já descritas anteriormente para as diferenças de médias. Como já ficou mostrado no teste de diferenças de médias que o período eleitoral sem incentivos confrontado com o período não eleitoral com incentivos não produz diferenças relevantes, não utilizamos esse modelo na regressão, remanescendo os três demais. 
Tabela 2

Modelos de regressão logística

\begin{tabular}{|c|c|c|c|c|c|c|c|c|}
\hline Modelo & $\begin{array}{c}\text { Variável } \\
\text { testada }\end{array}$ & B & S.E. & Wald & Sig. & Exp(B) & $\begin{array}{c}\mathbf{- 2} \text { Log } \\
\text { likelihood }\end{array}$ & $\begin{array}{c}\mathbf{R}^{\mathbf{2}} \\
\text { Nagelkerke }\end{array}$ \\
\hline 1 & $\begin{array}{c}\text { Incentivos } \\
\text { conteúdo } \\
\text { mensagem }\end{array}$ & 2,372 &, 319 & 55,237 &, 000 & 10,720 & 490,539 &, 187 \\
\hline 2 & $\begin{array}{c}\text { Período } \\
\text { eleitoral }\end{array}$ & 1,318 &, 221 & 35,489 &, 000 & 3,735 & 621,612 &, 082 \\
\hline 3 & Facebook & 2,219 &, 207 & 114,343 &, 000 & 9,196 & 772,279 &, 237 \\
\hline
\end{tabular}

Fonte: Elaboração própria a partir da base de dados do projeto: "Elites políticas e tecnologias digitais de uma perspectiva comparada".

Apesar de, nas diferenças de médias, o período eleitoral e o conteúdo da mensagem estarem no mesmo patamar, percebemos na regressão que o período eleitoral não teve um peso tão grande quanto esperávamos: embora tenha sido significativo, foi o mais baixo dos fatores testados. O modelo 2 indica que as chances de uma mensagem com incentivos ser respondida é três vezes maior em períodos eleitorais do que em períodos não eleitorais, ainda que ambas contenham incentivos para resposta. Mas o $\mathrm{R}^{2}$, baixo, explica somente 0,082 da distribuição das respostas.

Os dois modelos mais significativos apresentam resultados no mesmo patamar. $\mathrm{O}$ beta padronizado do modelo 1 indica que mensagens que, em seu conteúdo, têm incentivos eleitorais possuem dez vezes mais chances de serem respondidas do que mensagens com conteúdo técnico, sem incentivos eleitorais. Por fim, o modelo 3 indica que uma mensagem enviada por mídia social (Facebook) possui nove vezes mais chances de ser respondida, em comparação com uma mensagem enviada no mesmo período e com os mesmos incentivos via e-mail. Podemos concluir que, embora o período eleitoral exerça alguma influência, o que mais importa é o conteúdo da mensagem e a plataforma por meio da qual essa mensagem é enviada.

Contudo, eventualmente alguém pode questionar a constância desses efeitos sobre deputados com perfis distintos. Podemos ilustrar a questão dessas distinções com partido político. O Gráfico 3 apresenta a taxa de respostas por partido, para todos os contatos realizados: 
Gráfico 3

Porcentagem de respostas (todos tratamentos) por partido

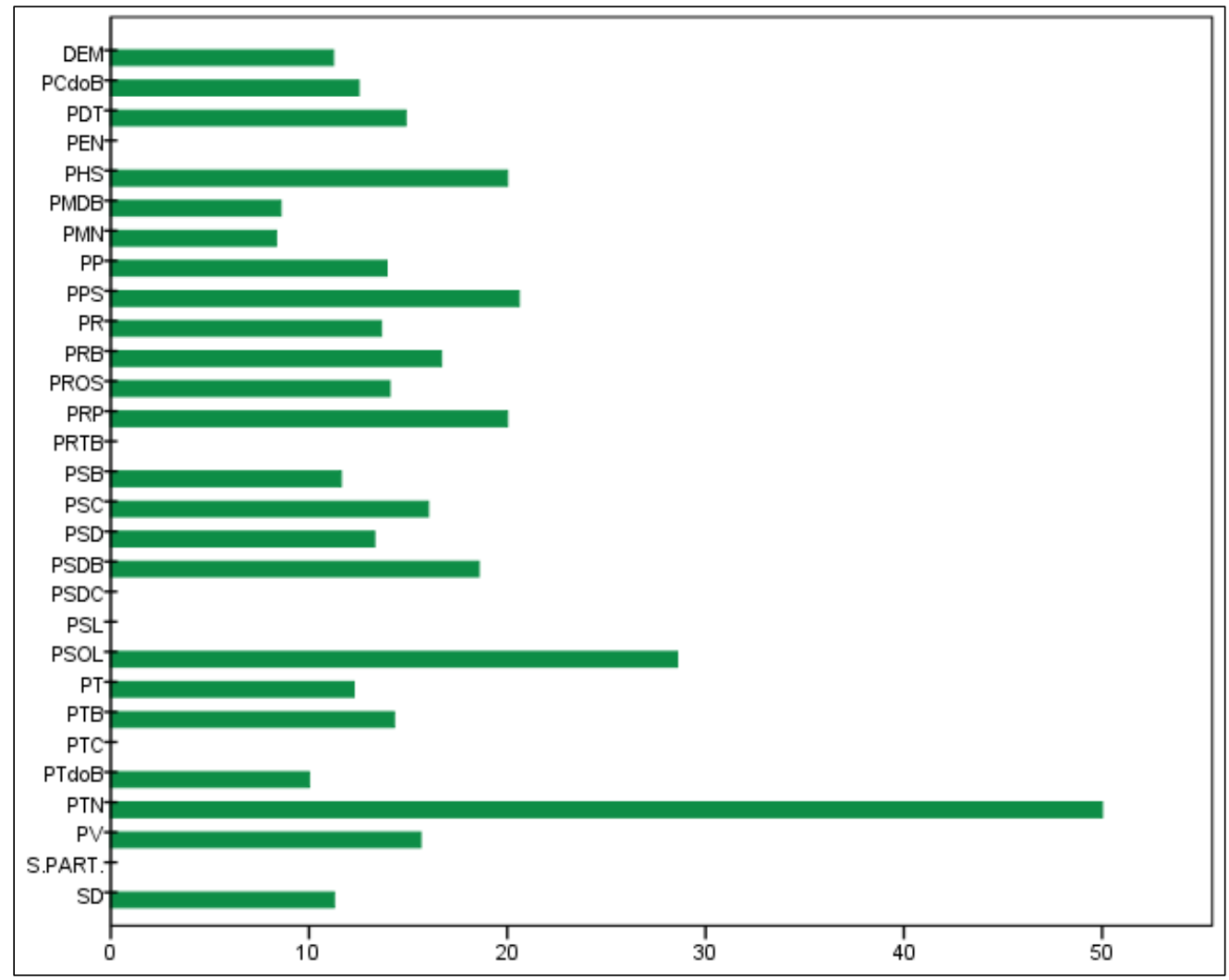

Fonte: Elaboração própria a partir da base de dados do projeto: "Elites políticas e tecnologias digitais de uma perspectiva comparada".

Embora seja possível, a partir das taxas de respostas por partidos, tentar visualizar algumas distinções e semelhanças, a simples porcentagem de respostas não indica diferença estatística, já que, por exemplo, pode ser afetada pelo número de respondentes em cada categoria (por exemplo, o PTN, que apresenta a taxa de respostas mais elevada, possuía apenas quatro deputados), consistindo o Gráfico 3 em apenas uma ilustração. Para identificar se, verdadeiramente, existem diferenças estatísticas intragrupos nos três modelos testados, realizamos o teste Ancova (análise de covariação) para 15 variáveis intervenientes, de perfil social e político dos parlamentares testados. A seguir apresentamos as variáveis intervenientes que utilizamos.

Idade

Essa variável indica se há distinções geracionais entre os deputados. Hipoteticamente, parlamentares mais jovens tenderiam a adotar de forma mais ampla as novas tecnologias para comunicar-se com seu eleitorado. 
Sexo

Essa variável aponta se há distinções em relação ao sexo do deputado ou deputada. Não é esperado, do ponto de vista da teoria dos incentivos racionais, que tal variável tenha qualquer influência.

\section{Escolaridade}

Essa variável se refere ao nível educacional do parlamentar, conforme autodeclaração ao TSE. Hipoteticamente, parlamentares com educação superior poderiam ser mais adeptos de novas tecnologias.

\section{Ocupação profissional}

Ocupação profissional autodeclarada ao TSE, classificada nos termos da proposta teórico-metodológica apresentada por Codato, Costa e Massimo (2014) de afinidade com a atividade política. Ela verifica se a classe social de origem do parlamentar, medida por meio do referido proxy, influi em sua ação de responder ou não aos contatos que realizamos.

\section{Titular/Suplente}

Essa variável indica se o parlamentar é titular do mandato ou suplente que assumiu posteriormente, conforme resultados eleitorais do TSE.

\section{Partido político}

Partido político, identificado sem agregações.

\section{Ideologia partidária}

Escala de ideologia política, com cinco níveis, que vai da esquerda à direita. A classificação realizada foi a seguinte: esquerda: PSOL; centro-esquerda: PT, PSB, PCdoB; centro: PV, PSDB, PPS, PMDB, PDT; centro-direita: PP, PR, PRB, PROS, PSD, PTB, PTC, SD; direita: DEM, PEN, PHS, PMN, PRP, PRTB, PSDC, PTdoB, PTN. Não classificado: Sem partido.

Tamanho do partido

Dado pelo número de deputados no momento do contato. Testa se o tamanho da estrutura partidária pode exercer influência nos resultados. 


\section{Governo/Oposição}

Posição do partido em relação ao executivo federal. Hipoteticamente, estar na oposição seria um incentivo para ser mais responsivo perante o eleitorado.

\section{Protagonismo}

Essa variável testa se deputados com atuação mais destacada e notória liderança exercem alguma influência no modelo. A variável separa os deputados de atuação mais destacada daqueles de atuação medíocre, entre os quais inclui-se o chamado baixo clero. Para essa variável, foi utilizada a classificação realizada pelo Departamento Intersindical de Assessoria Parlamentar (Diap) e disponibilizada em sua publicação anual (Diap, 2015). Hipoteticamente, os deputados de maior atuação podem ter maior preocupação em responder aos seus eleitores, dada sua preocupação reputacional.

Um achado correlato foi o de Marques, Aquino e Miola (2014), que argumentaram que exercer funções de liderança era um dos aspectos mais preditivos para atuação em redes sociais, naquele caso, o Twitter. Embora existam distinções entre a variável desses autores e a nossa, elas podem caminhar paralelamente, já que procuram medir aspectos semelhantes.

\section{Magnitude do distrito}

Magnitude do estado do deputado. Hipoteticamente, deputados vindos de estados com maior magnitude tenderiam a ser menos accountables em relação àqueles vindos de distritos de menor magnitude, conforme hipótese erguida por Carey (2016).

\section{Competição eleitoral}

Índice de competição eleitoral do estado do deputado. Hipoteticamente, deputados vindos de estados com maior competição teriam mais incentivos para serem responsivos aos eleitores.

A competição eleitoral é medida pelo número efetivo de candidatos, aplicando-se a mesma fórmula do número de partidos efetivos:

$$
N=\frac{1}{\sum_{i=1}^{n} P i^{2}}
$$

Fonte: Laakso e Taagepera (1979).

onde $\mathrm{Pi}^{2}$ é o quadrado da proporção de votos de cada candidato $i$. Para tornar os dados comparáveis entre estados com distintas magnitudes, utilizamos neste artigo o número de candidatos efetivos pelo número de cadeiras disponíveis em cada estado. Dessa forma, o 
valor será sempre igual a 1 quando houver o mesmo número de candidatos efetivos e cadeiras, negativo, quando houver mais cadeiras do que candidatos reais e positivo na situação inversa. Quando houver maior número de candidatos que de cadeiras, o valor será 2, e assim por diante.

\section{Densidade eleitoral}

Dada pela porcentagem de votos obtidos pelo deputado em sua eleição. Hipoteticamente, parlamentares com maior densidade, portanto, possuindo maior base eleitoral, tenderiam a possuir maior capital político e, como consequência da preocupação reputacional, serem mais responsivos.

\section{Concentração eleitoral}

Índice de concentração/dispersão eleitoral, que mede se o parlamentar foi eleito por um "distrito informal" (Ames, 1995b, 1995a) ou votação dispersa por todo o estado. Hipoteticamente, deputados com alta concentração eleitoral tendem a adotar práticas de pork barrell e, portanto, tenderiam a responder menos mensagens que chegam por e-mail e mídias sociais. Para medir isso, utilizamos o índice G de Florence, calculado da seguinte forma:

$$
G=\sum_{M}\left(\frac{V d m}{V d}-\frac{V m}{V t}\right)^{2}
$$

Fonte: Avelino, Biderman e Silva (2011).

onde Vdm são os votos do candidato no município, Vd são os votos totais do candidato, $V m$ é o total de votos do município e Vt é o total de votos no distrito eleitoral.

\section{Receitas de campanha}

Valor das receitas de campanha. Hipoteticamente, maior receita de campanha pode indicar estrutura organizacional mais bem definida e profissionalizada, o que poderia se refletir na capacidade do staff do parlamentar de responder às demandas. Para comparar adequadamente as receitas entre diferentes estados, utilizamos o índice proposto por Sachett e Speck, calculado da seguinte forma:

$$
I S R=\frac{R c \cdot N c}{R t}
$$

Fonte: Sachett e Speck (2012). 
onde Rc são as receitas do candidato, Nc é o número de candidatos no pleito e Rt, o total de receitas de todos candidatos naquele pleito.

A seguir, apresentamos os resultados gerais do teste Ancova. Os três modelos foram rodados de forma separada, tal como a regressão da Tabela 2, mas colocados na Tabela 3 por uma questão de síntese. No Anexo, podem-se consultar os detalhes dos resultados completos de cada teste.

Tabela 3

Análise de covariância

\begin{tabular}{|c|c|c|c|c|c|c|}
\hline \multirow[b]{2}{*}{ Variáveis } & \multicolumn{2}{|c|}{ Modelo 1} & \multicolumn{2}{|c|}{ Modelo 2} & \multicolumn{2}{|c|}{ Modelo 3} \\
\hline & $\begin{array}{c}\text { Qui- } \\
\text { quadrado } \\
\text { de Wald }\end{array}$ & Sig. & $\begin{array}{c}\text { Qui- } \\
\text { quadrado } \\
\text { de Wald }\end{array}$ & Sig. & $\begin{array}{c}\text { Qui- } \\
\text { quadrado } \\
\text { de Wald }\end{array}$ & Sig. \\
\hline (Intercept) & 3,452 &, 063 & 2,810 & ,094 & 1,096 & ,295 \\
\hline Tratamento & 36,637 &, 000 & 12,603 &, 000 & 81,165 & 0,000 \\
\hline Idade & 2,958 & ,085 & 3,071 & ,080 & 2,737 & ,098 \\
\hline Sexo & ,009 & 924 & ,023 & 881 &, 540 & 463 \\
\hline Escolaridade & 185 & 667 & 319 & ,572 & ,956 & 328 \\
\hline Ocupação profissional & ,296 & ,587 & 1,686 & ,194 & 4,201 &, 040 \\
\hline Titular / Suplente & ,513 & ,474 & 748 & ,387 & ,086 & 770 \\
\hline Partido & ,097 & 756 & ,358 &, 550 & 2,921 & 087 \\
\hline Ideologia &, 030 & 863 & ,073 & ,787 & ,529 & ,467 \\
\hline Tamanho do partido & 173 & 677 & 167 & ,682 & 3,077 & 079 \\
\hline Governo / Oposição &, 002 & 961 & 149 & 700 & ,494 & 482 \\
\hline Protagonismo & 4,828 &, 028 & 2,900 & ,089 & 1,064 & ,302 \\
\hline Magnitude & ,950 & ,330 & 1,114 & 291 & ,427 &, 514 \\
\hline Competição eleitoral & ,328 & ,567 & 1,098 & 295 & 996 & 318 \\
\hline Densidade eleitoral &, 358 &, 550 &, 063 & 802 & ,494 & ,482 \\
\hline Concentração eleitoral & ,238 &, 625 &, 048 & 827 &, 026 & 873 \\
\hline Receitas de campanha & 2,432 & 119 & 1,473 & ,225 & ,005 & ,945 \\
\hline
\end{tabular}

Fonte: Elaboração própria. Base de dados do projeto: "Elites parlamentares e tecnologias digitais de uma perspectiva comparada" (Grupo de Pesquisa sobre Atores, Instituições Políticas e Tecnologias Digitais Geist).

Como se percebe pelos resultados nos $p$-values, dos três modelos, com 15 variáveis cada, apenas em dois casos há força estatística para afirmar que a variação intragrupo não se deve a uma distribuição aleatória. No modelo 1 (conteúdo da mensagem), a variável significativa é "protagonismo". E no modelo 3 (meio), a variável significativa é "ocupação profissional". Ou seja, quando se trata de mensagens cujo conteúdo tem incentivos eleitorais, políticos apontados como "protagonistas" do Congresso (com atuação mais destacada) tendem a responder mais. E, quando se trata do meio (e- 
mail versus Facebook), deputados com ocupações profissionais classificadas nos níveis mais altos de afinidade com a atividade política (categoria mais elevada na qual se encontram os políticos profissionais) tendem a responder mais pelo Facebook. Ou seja, políticos profissionais tendem a responder mais pelo Facebook, comparativamente aos deputados com outras origens profissionais. Pelos dados, podemos verificar que a maioria dos fatores não incide sobre a responsividade dos parlamentares por distintas mídias. Com efeito, apenas protagonismo (no modelo 1) e ocupação (no modelo 3) tiveram índices significativos. Isso equivale a afirmar que parlamentares mais influentes nas deliberações do Congresso e com maior expertise política prévia tendem a interagir mais com os cidadãos por intermédio das mídias digitais e da internet, especialmente no caso das mídias sociais comentadas.

\section{Discussão}

Apresentamos, inicialmente, três hipóteses centrais sobre nossas variáveis, além da quarta hipótese que versava somente sobre a variância dos resultados em conjunto com outras variáveis. À luz dos resultados, podemos constatar que a primeira, a terceira e a quarta se confirmaram de forma consistente: políticos tendem a responder mais a mensagens que possuem em seu conteúdo incentivos eleitorais e tendem a responder mais mensagens enviadas por meio de mídias sociais (Facebook). E esses resultados não são afetados por aspectos sociais e políticos de cada parlamentar. A segunda hipótese, de que políticos tendem a responder mais a mensagens em períodos eleitorais, embora possua resultados positivos, é apenas parcialmente mantida, devido aos baixos valores obtidos nos testes apresentados. Nesta seção, discutimos algumas implicações teóricas dos principais resultados.

Começando pelo fim, a quarta hipótese, podemos afirmar que os dados a confirmam. Isto é, colocados sob os mesmos incentivos racionais, parlamentares, mesmo com distintos perfis sociais e políticos, tendem a reagir de forma semelhante. Ou, colocado de forma mais precisa, tais perfis não apresentaram força estatística para explicar a variação intragrupo entre as variáveis explicativas testadas. Esse resultado é um achado importante, se considerarmos que fatores como idade já foram considerados marcadores importantes para explicar o uso de ferramentas digitais. Isso também corrobora a força do modelo baseado em incentivos.

Prosseguindo na análise, podemos nos atentar à taxa de resposta que obtivemos. Ela apresenta dois patamares distintos, que podemos cotejar com resultados de estudos análogos ao redor do mundo. Nos e-mails, obtivemos respostas que variam de $2,3 \%$ a $14,8 \%$. Esses valores estão muito abaixo de resultados encontrados nos Estados Unidos, 42,3\% (Broockman, 2013), em países europeus, entre 35\% e 41\% (Vaccari, 2014), ou $36 \%$ na Suíça (Lloren, 2017). No entanto, são patamares muito próximos aos $12,9 \%$ encontrados na África do Sul (Mcclendon, 2016). Contudo, quando verificamos a taxa de respostas que obtivemos nas mídias sociais, de $29,8 \%$, percebemos que o nível de 
respostas sobe para um patamar próximo ao dos estudos citados sobre a responsividade aos e-mails nos Estados Unidos e na Europa.

Essa comparação com os resultados da literatura pode indicar duas hipóteses, a serem testadas no futuro. Primeiro, talvez possa existir uma distinção entre países desenvolvidos, cujos representantes tenderiam a ter maior responsividade, e países em desenvolvimento, cuja taxa de responsividade é menor. Essa é uma possibilidade de abordagem futura em estudos comparativos. Segundo, a comparação desses resultados parece indicar que, independentemente do contexto, talvez exista um "teto" em quão responsivos os parlamentares sejam.

Nossa primeira hipótese, sobre o conteúdo da mensagem, pode ser explicada pelos incentivos racionais (eleitorais). Downs (2013) escreveu que políticos não se elegem para fazer políticas públicas, mas sim fazem políticas públicas para se (re)eleger. Isto é, o primeiro objetivo de um político é obter e manter o poder. Dessa forma, os deputados federais brasileiros tendem a reagir e ser responsivos aos eleitores de modo substancialmente maior quando existem incentivos eleitorais em jogo. Curiosamente, isso vai em sentido contrário aos achados de Vaccari (2014), que não encontrou influência dos incentivos eleitorais em seu experimento. Nossos achados, no entanto, dialogam bem com os de Broockman (2013). Esse autor mostrou que, enquanto existem incentivos eleitorais (que ele chama incentivos extrínsecos), o comportamento de congressistas brancos e negros é estatisticamente indistinguível.

Nossa terceira hipótese versa sobre o meio pelo qual é realizado o contato. Sobre os resultados em relação à plataforma de mídias sociais, existem três explicações possíveis para esses resultados, não excludentes entre si. A primeira, mais simples, remete à ascensão dessas ferramentas e a seu uso intenso, tanto pela população quanto pela elite política, como outros estudos já apontaram para o caso brasileiro (Braga, Rocha e Vieira, 2015; Carlomagno, 2015). Como dito, a arquitetura das redes digitais é fortemente ancorada em princípios de interação, participação e transparência de todos os seus usuários (Chadwick, 2009). Isso tende a significar que, se determinado ator ignora as formas de interação, não responde às demandas de outros usuários e não é transparente em absoluto, ele poderá ser rechaçado pelos outros participantes. Atores políticos, apesar do receio de perder o controle do fluxo e da direção da comunicação (Stromer-Galley, 2014), teriam então interesse em ser atores ativos nas mídias sociais, precisando, assim, obedecer à sua lógica para alcançar bons resultados em termos de visibilidade, reputação e influência nesses meios (Aggio, 2015; Coleman e Brumler, 2009; Marques e Sampaio, 2011). Todavia, parece ser uma explicação limitada e, mesmo, contestável ${ }^{11}$.

\footnotetext{
11 Por exemplo, ao analisar as diferentes campanhas online nos Estados Unidos, Stromer-Galley (2014) defende que chegamos, no máximo, a um modelo de "interatividade controlada". Na prática, as campanhas interagem em algum nível, porque agentes e meios demandam isso dos candidatos, mas essa interação ocorre em pouca intensidade e dentro de temas e agendas controladas, que sejam do interesse direto das campanhas.
} 
Uma segunda explicação, mais cética, poderia ser que a demanda de trabalho para o gerenciamento dos contatos via mídias sociais ainda não é tão grande, em termos de fluxo de informações, possibilitando respostas mais ágeis se comparada ao e-mail, por onde chega um montante substancialmente maior de mensagens - nas quais se incluem "correntes", mensagens repassadas automaticamente para muitas listas de e-mails, o que não é ainda usual no Facebook, e a pressão realizada pelos intermediários digitais, como é o caso do Avaaz. Além disso, o Facebook propicia uma navegação mais informal e lúdica na internet por parte do cidadão comum, além dificultar o anonimato e facilitar a identificação de fakes e de spams, o que pode servir como um incentivo para o uso dessa ferramenta pelos políticos em geral e pelos deputados em particular. Com efeito, como apontam outros estudos (Braga, Rocha e Vieira, 2015; Carlomagno, 2015), o Facebook já é há algum tempo a plataforma preferida pelos deputados e seus assessores para interagir com o cidadão, tanto em período eleitoral como fora dele.

Em terceiro, a explicação de caráter organizacional nos parece importante. Pode ser que o Facebook seja mais eficaz pois, geralmente, os responsáveis pelas comunicações via mídias sociais são diferentes dos responsáveis por checar e responder os e-mails. A comunicação via mídias sociais é majoritariamente - para não dizer exclusivamente - com o eleitor/cidadão, podendo ser, portanto, de acesso exclusivo do responsável pela comunicação de gabinete. Carlomagno (2015) argumentou que gabinetes parlamentares tendem a possuir assessores dedicados especificamente a gerenciar a presença online nas mídias sociais dos deputados. Dessa forma, o contato é mais direto e a resposta mais ágil. O e-mail, por outro lado, recebe muitas mensagens de natureza distinta, como já argumentamos, desde contatos dos cidadãos, passando por informes, convites para cerimônias e eventos, contatos de aliados políticos, imprensa, e um longo et cetera (Marques, 2007). Dessa forma, o responsável usualmente é alguém de cargo distinto, que redistribui os e-mails a depender do tema. Nisso, potencialmente menos respostas podem ser obtidas.

Acreditamos que esses três aspectos, complementares, trabalhem em conjunto para explicar por que deputados - e suas assessorias - tendem a ser mais responsivos em mídias sociais do que através de e-mails.

\section{Considerações finais}

Este artigo mostra os resultados de um experimento conduzido para identificar quais fatores levam os políticos a responder aos contatos dos cidadãos que chegam aos seus gabinetes. Nossa primeira e terceira hipóteses foram confirmadas. Políticos têm dez vezes mais chance de responder a mensagens que possuem em seu conteúdo incentivos eleitorais do que a mensagens sobre projetos de lei, com aspectos técnicos. Políticos também têm nove vezes mais chance de responder a mais mensagens enviadas por meio de mídias sociais do que às enviadas por e-mail. 
Nossa segunda hipótese foi apenas parcialmente confirmada, de modo muito fraco. Embora políticos tendam, de fato, a responder mais mensagens em períodos eleitorais, os valores dos testes, embora estatisticamente significativos, não possuem robustez.

Isso indica que, primeiro, mais importante do que o período (eleitoral ou não) em si são os incentivos objetivos que a mensagem contém. Segundo, indica que, como os pesquisadores de internet têm apontado, de fato, as mídias sociais são um canal de comunicação efetivo entre população e representantes (Braga, Rocha e Vieira, 2015).

Apesar disso, a taxa de respostas é muito reduzida no geral. Em termos mais amplos, a contribuição deste artigo consiste em discutir as implicações desse fato. Em tempos em que tanto se fala sobre uma suposta crise de representação, podemos resgatar a observação de Coleman e fazer nossas suas palavras: "The problem might not be permanent representation per se, but the weak and inappropriate modes of mediation that support it" (Coleman, 2005, p. 181). Isto é, a representação necessita conectar os atores políticos e os cidadãos representados. Nisso, o pressuposto básico é a existência de comunicação entre as duas partes e o fortalecimento das ferramentas - básicas ou mais sofisticadas - para que isso ocorra.

Dito de outra forma, quando deputados (ou quaisquer outros membros da elite política) oferecem contatos de e-mail, perfis em redes sociais online ou mantêm algum tipo de plataforma digital, isso gera a expectativa difusa de que sejam canais oficiais e significativos de interação entre representantes e representados, e, consequentemente, que possam ser usados para alguns fins de monitoramento e responsabilização do exercício do mandato. O não cumprimento dessa expectativa, no limite, pode gerar efeitos contrários aos esperados originalmente com os usos das tecnologias digitais; ou seja, a diminuição, e não o aumento, da confiança dos cidadãos em seus representantes e instituições políticas. Por outro lado, nosso artigo mostra que, além da vontade política do parlamentar e de seu staff de empreender essa interação, há um segundo elemento a ser levado em conta: a expertise dos cidadãos em utilizar a ferramenta adequada para estabelecer esses canais de participação e expressar suas demandas, o que envolve um processo incremental de aprendizado do uso das ferramentas digitais para fins políticos. Os dados apresentados em nosso experimento evidenciam que o e-mail pode não ser a ferramenta mais adequada para o estabelecimento desse tipo de interação, mesmo em períodos eleitorais.

A abordagem experimental com parlamentares e, especificamente, sua responsividade em plataformas digitais são uma seara aberta a pesquisas na ciência política brasileira. Os futuros interessados podem testar uma série de outros incentivos ou variáveis independentes. As diferenças no plano da política subnacional, que continuam sendo grandes, são um amplo campo de pesquisa ainda a ser explorado. Finalmente, como já observado, a comparação entre Brasil e países com democracia mais consolidada é outra área que ainda carece de pesquisas e resultados, assim como estudos longitudinais que observem eventuais movimentos incrementais em direção a um aumento da responsividade e accountability dos políticos através do uso de suas ferramentas digitais. 


\section{Referências bibliográficas}

AGGIO, C. "Os candidatos ainda evitam a interação? Twitter, comunicação horizontal e eleições brasileiras". E-Compós, vol. 18, n 1, p. 1-22, 2015.

AlDÉ, A.; SAntos, J. G. B. "Petições públicas e batalhas digitais". Anais do XXI Encontro Anual da Compós, Juiz de Fora, 2012.

ALPERIN, D. J.; SCHULTZ, D. "E-democracy: legislative-constituent communications in minnesota and wisconsin". The annals of the Annual Meeting of the American Political Science Association, 2003.

AMES, B. "Electoral strategy under open-list proportional representation". American Journal of Political Science, vol. 39, n² 2, p. 406, 1995a.

. "Electoral rules, constituency pressures, and pork barrel: bases of voting in the Brazilian congress". The Journal of Politics, vol. 57, $\mathrm{n}^{\circ} 2$, p. 324-343, 1995b.

AVelino, G.; Biderman, C.; Silva, G. P. "A concentração eleitoral nas eleições paulistas: medidas e aplicações". Dados, vol. 54, n² 2, p. 319-347, 2011.

BERGMAN, T., et al. Democratic delegation and accountability: cross-national patterns. In: STRøM, K.; MüLLER, W. C.; BERGMAN, T. (eds.). Delegation and accountability in parliamentary democracies. New York: Oxford University Press, 2006.

BRAGA, S.; NiColÁs, M. A.; BECHER, A. R. "Clientelismo, internet e voto: personalismo e transferência de recursos nas campanhas online para vereador nas eleições de outubro de 2008 no Brasil".

Opinião Pública, vol. 19, n 1, p. 168-197, 2013.

BRAGA, S.; ROCHA, L.; VIEIRA, F. "'Americanização' da representação política virtual? Um estudo comparado das estratégias de comunicação digital por parlamentares de diferentes sistemas políticos". Anais do 39० Encontro Nacional da Anpocs, Caxambu, 2015.

BROOCKMAN, D. E. "Black politicians are more intrinsically motivated to advance blacks' interests: a field experiment manipulating political incentives". American Journal of Political Science, vol. 57, $\mathrm{n}^{\circ}$ 3, p. 521-536, 2013.

Butler, D. M.; KARPOWITZ, C. F.; Pope, J. C. "A field experiment on legislators' home styles: service versus policy". The Journal of Politics, vol. 74, $n^{\circ} 2$, p. 474-486, 2012.

CARDY, E. A. "An experimental field study of the GOTV and persuasion effects of partisan direct mail and phone calls". The annals of the American Academy of Political and Social Science, vol. 601, $\mathrm{n}^{\circ} 1$, p. $28-40,2005$.

CAREY, J. M. "Legislative accountability: should Brazil break up its big electoral districts?". E-Legis, vol. 19, no 1, p. 72-86, 2016.

CARLomAgno, M. C. "Por dentro dos gabinetes: organização e profissionalização das assessorias parlamentares em mídias sociais". Dissertação de mestrado em Ciência Política. Universidade Federal do Paraná. Curitiba, 2015.

CARREIRO, R. "A discussão política em rede: um estudo sobre a divergência política no Facebook". Tese de Doutorado em Comunicação e Cultura Contemporâneas. Universidade Federal da Bahia. Salvador, 2017.

Cervi, E. U.; MAssuchin, M. G.; Carvalho, F. C. (eds.). Internet e eleições no Brasil. Curitiba: CPOP (grupo de pesquisa em Comunicação Política e Opinião Pública), 2016. 
RESPONDEM OS POLÍTICOS A QUESTIONAMENTOS DOS ELEITORES?

CHADWICK, A. "Web 2.0: new challenges for the study of e-democracy in an era of informational exuberance". I/S: a Journal of Law and Policy, vol. 5, n 1, p. 9-42, 2009.

COLEMAN, S. "New mediation and direct representation: reconceptualising representation in the digital age". New Media and Society, vol. 7, n² 2, p. 177-198, 2005.

Coleman, S.; Brumler, J. G. The internet and democratic citizenship: theory, practice and policy. Cambridge: Cambridge University Press, 2009.

Coleman, S.; Moss, G. "Governing at a distance - politicians in the blogosphere". Information Polity, vol. $13, n^{\circ} 1-2$, p. 7-20, 2008.

Conroy, M.; FeezelL, J. T.; Guerrero, M. "Facebook and political engagement: a study of online political group membership and offline political engagement". Computers in Human Behavior, vol. 28, n० 5, p. 1.535-1.546, 2012.

COUPER, M. P. "Web surveys: a review of issues and approaches". Public Opinion Quarterly, vol. 64, p. $464-494,2000$.

DADER, J. L. "Ciberdemocracia y ciberparlamento. El uso de correo electrónico entre los parlamentarios espanõles y ciudadanos comunes (1999-2001)". Telos, n 55, 2003.

DiAP - Departamento Intersindical de Assessoria Parlamentar. "Os 'Cabeças' do Congresso Nacional: uma pesquisa sobre os 100 parlamentares mais influentes". Coord. Antônio Augusto de Queiroz. 22a ed. Brasília, 2015. Disponível em: <http://www.diap.org.br/index.php/agencia-diap/13200-diapdivulga-relacao-dos-100-parlamentares-mais-influentes>. Acesso: dez. 2015 a dez. 2016).

Downs, A. Uma teoria econômica da democracia. São Paulo: Edusp, 2013.

ELlison, N. B.; STEINFIELD, C.; LAMPE, C. "Connection strategies: social capital implications of Facebook-enabled communication practices". New Media \& Society, vol. 13, n 6, p. 873-892, 2011.

Ferber, P.; Foltz, F.; Pugliese, R. "The internet and public participation: state legislature web sites and the many definitions of interactivity". Bulletin of Science, Technology \& Society, vol. 25, $\mathrm{n}^{\circ} 1, \mathrm{p}$. 85-93, 2005.

"Cyberdemocracy and online politics: a new model of interactivity". Bulletin of Science, Technology \& Society, vol. 27, n 5, p. 391-400, 2007.

FRANÇA, A. S. T.; MARTins, F. R. S.; BRAGA, S. "O impacto da internet no funcionamento das instituições representativas: o caso do Paraná". Mediações, vol. 11, n² 2, p. 163, 2006.

Gerber, A. S.; Green, D. P. "The effects of canvassing, telephone calls, and direct mail on voter turnout: a field experiment". American Journal of Political Science, vol. 94, n 3, p. 653-663, 2000.

Gerber, A. S.; Green, D. P.; Green, M. "Partisan mail and voter turnout: results from randomized field experiments". Electoral Studies, vol. 22, p. 563-579, 2003.

GiBSON, R. K. "Party change, social media and the rise of 'citizen-initiated'campaigning". Party Politics, vol. 21, n², p. 183-197, 2015.

Gomes, W. Transformação da política na era da comunicação de massa. São Paulo: Paulus, 2004.

HALPERN, D.; GiBBS, J. "Social media as a catalyst for online deliberation? Exploring the affordances of Facebook and YouTube for political expression". Computers in Human Behavior, vol. 29, n 3, p. $1.159-1.168,2012$.

Hindman, M. The myth of digital democracy. New Jersey: Princeton University Press, 2009. 
MÁRCIO CUNHA CARLOMAGNO; SERGIO SOARES BRAGA; RAFAEL CARDOSO SAMPAIO

KAID, L. L.; POSTELniCU, M. "Political advertising in the 2004 election comparison of traditional television and internet messages". American Behavioral Scientist, vol. 49, n² 2, p. 265-278, 2005.

LAAKSO, M.; TAAGEPERA, R. "'Effective' number of parties: a measure with application to West Europe". Comparative Political Studies, vol. 12, no 1, p. 3-27, 1979.

Lederman, D.; LoAyzA, N. V.; SOARES, R. R. "Accountability and corruption: political institutions matter". Economics \& politics, vol. 17, n 1, 2005.

LILLEKER, D. G.; JACKSON, N. A. "Interacting and representing: can Web 2.0 enhance the roles of an MP?". The Annals of ECPR Joint Sessions. Lisbon, 2009.

LLOREN, A. "Does direct democracy increase communicative responsiveness? A field experiment with Swiss politicians". Research and Politics, vol. 4, n 1, p. 1-8, 2017.

Loewen, P. J.; Rubenson, D.; WANTCHEKON, L. "Help me help you: conducting field experiments with political elites". The Annals of the American Academy of Political and Social Science, vol. $628, \mathrm{n}^{\circ} 1$, p. 165-175, 2010.

LUSOLI, W.; WARD, S.; GIBSON, R. "(Re)connecting politics? parliament, the public and the internet". Parliamentary Affairs, vol. 59, n 1, p. 24-42, 2006.

LYNE, M. M. Rethinking economics and institutions: the voter's dilemma and democratic accountability. In: KITSCHELT, H.; WiLKINSON, S. I. (eds.). Patrons, clients, and policies: patterns of democratic accountability and political competition. Cambridge: Cambridge University Press, 2007.

MAIA, R., et al. "Sobre a importância de examinar diferentes ambientes online em estudos de deliberação". Opinião Pública, vol. 21, n², 2015.

MANIN, B. "As metamorfoses do governo representativo". Revista Brasileira de Ciências Sociais, vol. $10, n^{\circ} 29$, p. 5-34, 1995.

2013. . "A democracia do público reconsiderada". Novos Estudos Cebrap, n 97, p. 115-127,

MAnSbridge, J. "Rethinking representation". The American Political Science Review, vol. 97, $\mathrm{n}^{\circ} 4$, $\mathrm{p}$. 515-528, 2003.

MARqueS, F. P. J. A. "Internet e oportunidades de participação política - um exame dos websites de senadores brasileiros e norte-americanos". Revista Fronteiras, vol. 9, p. 155-166, 2007.

MARques, F. P. J. A.; Aquino, J. A. D.; MiolA, E. "Parlamentares, representação política e redes sociais digitais". Opinião Pública, vol. 20, no 2, p. 178-203, 2014.

MARQUeS, F. P. J. A.; MiolA, E. "Internet e parlamento: um estudo dos mecanismos de participação oferecidos pelo Poder Legislativo através de ferramentas online". E-Compós, vol. 9, p. 1-20, 2007.

Marques, F. P. J. A.; Sampaio, R. C. "Internet e eleições 2010 no Brasil: rupturas e continuidades nos padrões mediáticos das campanhas políticas online". Galáxia, vol. 22, p. 208-221, 2011.

MARTINS, F. R. S. "A influência do e-mail sobre as decisões dos parlamentares brasileiros: um estudo sobre a tramitação do Projeto de Lei da Biossegurança". Monografia de Especialização em Sociologia Política. Universidade Federal do Paraná. Curitiba, 2005.

MCCLENDON, G. H. "Race and Responsiveness: an experiment with South African politicians". Journal of Experimental Political Science, vol. 3, p. 60-74, 2016.

Miguel, L. F. "Impasse da accountability: dilemas e alternativas da representação política". Revista 
RESPONDEM OS POLÍTICOS A QUESTIONAMENTOS DOS ELEITORES?

de Sociologia e Política, vol. 25, p. 25-38, 2005.

MÜLLER, W. C. "Political parties in parliamentary democracies: making delegation and accountability work". European Journal of Political Research, vol. 37, n 3, p. 309-333, 2000.

MULLINIX, K. J., et al. "The generalizability of survey experiments". Journal of Experimental Political Science, vol. 2, n² 2, p. 109-138, 2015.

NORTON, P. "Four models of political representation: British MPs and the use of ICT'". The Journal of Legislative Studies, vol. 13, nº 3, p. 354-369, 2007.

PANAGOPOULOS, C. "Partisan and nonpartisan message content and voter mobilization: field experimental evidence". Political Research Quarterly, vol. 62, n 1, p. 70-76, 2009.

Pereira, M. A.; Marona, M.; Pinheiro, P. C. "Fale com o deputado? Uma análise do perfil dos parlamentares em relação à interação virtual com os cidadãos". Anais do $35^{\circ}$ Encontro Anual da Anpocs, Caxambu, 2011.

Perna, A.; Braga, S. The invisible side of political participation. In: SobacI, M. Z. (ed.). E-Parliament and ICT-Based Legislation. [s.I.] IGI Global, 2012.

PITKIN, H. F. The concept of representation. Berkeley: University os California Press, 1967.

PReECE, J. R.; StodDaRD, O. B. "Does the message matter? A field experiment on political party recruitment". Journal of Experimental Political Science, vol. 2, p. 26-35, 2015.

SACCHET, T.; SPECK, B. W. "Financiamento eleitoral, representação política e gênero: uma análise das eleições de 2006". Opinião Pública, vol. 18, n 1, p. 177-197, 2012.

SCHEDleR, A. Conceptualizing accountability. In: SCHEDleR, A.; DiAMOND, L.; PLATTNER, M. F. (eds.). The self-restraining state: power and accountability in new democracies. Boulder/London: Lynne Rienner Publishers, 1999.

SEABRIGHT, P. "Accountability and decentralisation in government: an incomplete contracts model". European Economic Review, vol. 40, p. 61-89, 1996.

SILVA, S. P. "Graus de participação democrática no uso da internet pelos governos das capitais brasileiras". Opinião Pública, vol. 2, n 11, p. 450-468, 2005.

SNYDER JR., J. M.; STRÖMBERG, D. "Press coverage and political accountability". Journal of Political Economy, vol. 118, no 2, p. 355-408, 2010.

SPADA, P.; GUIMARÃES, F. de S. "Investigating elite behavior through field answer more to core or swing voters?". Brazilian Political Science Review, vol. 7, n 1, p. 56-73, 2013.

STÁBILE, M. "Democracia eletrônica para quem? Quem são, o que querem e como os cidadãos avaliam o portal da Câmara dos Deputados". Dissertação de Mestrado em Ciência Política. Universidade de Brasília, Brasília, 2012.

STROMER-Galley, J. "On-line interaction and why candidates avoid it". Journal of communication, vol. $50, n^{\circ} 4,2000$.

Presidential campaigning in the internet age. Oxford: Oxford University Press, 2014.

TURGEON, M.; RENNÓ, L. "Informação política e atitudes sobre gastos governamentais e impostos no Brasil: evidências a partir de um experimento de opinião pública". Opinião Pública, vol. $16, \mathrm{n}^{\circ} 1$, p. 143-159, 2010.

VACCARI, C. "You've got (no) mail: how parties and candidates respond to email inquiries in Western 
MÁRCIO CUNHA CARLOMAGNO; SERGIO SOARES BRAGA; RAFAEL CARDOSO SAMPAIO

democracies". Conference chasing the digital wave: international lessons for the UK 2015 Election Campaign, London, 2012.

VACCARI, C. "You've got (no) mail: how parties and candidates respond to email inquiries in western democracies". Journal of Information, Technology \& Politics, vol. 11, n² 2, p. 245-258, 2014.

VIDIGAL, R. L. "Medindo assuntos socialmente sensíveis: o uso do experimento de lista e políticas de ação afirmativa". Revista Eletrônica de Ciência Política, vol. 6, nº 1, 2015.

WARD, S.; LUSOLI, W. "From weird to wired: MPs, the internet and representative politics in the UK". The Journal of Legislative Studies, vol. 11, n 1, p. 57-81, 2005.

Williamson, A. "The effect of digital media on MPs' communication with constituents". Parliamentary Affairs, vol. 62, n³, p. 514-527, 2009a.

MPs online; connecting with constituents. A study into how MPs use digital media to communicate with their constituents. London: Microsoft/Hansard Society, 2009b.

Woon, J. "Democratic accountability and retrospective voting: a laboratory experiment". American Journal of Political Science, vol. 56, n 4, p. 913-930, 2012.

Zucco JR., C. Noções de desenho de pesquisa: experimentos, quase experimentos e estudos observacionais. Brasília: Cefor, 2013 


\section{Anexo}

Quadro 2

\section{Conteúdo das mensagens}

\begin{tabular}{|c|c|}
\hline Mensagem & Conteúdo das mensagens \\
\hline 1 & $\begin{array}{l}\text { Olá, } \\
\text { Me lembro que votei [no senhor/na senhora] em 2010, por indicação da minha } \\
\text { falecida irmã, mas não acompanho muito política, não entendo direito. } \\
\text { Eu disse pro meu filho que ia votar novamente e ele disse pra eu mandar um e- } \\
\text { mail perguntando o que você fez neste tempo de mandato ou o que defendeu, pra } \\
\text { eu saber se valia a pena. } \\
\text { Você pode me responder alguma coisa, pra eu dizer pro meu filho? Queria saber o } \\
\text { que você fez nestes últimos anos? }\end{array}$ \\
\hline 2 & $\begin{array}{l}\text { Olá [deputado/deputada], } \\
\text { Qual sua posição a respeito do pré-sal? Li que há um debate a respeito de qual o } \\
\text { melhor modelo de partilha ou concessão e gostaria de saber qual sua posição, } \\
\text { para o futuro, e como já votou neste tema. } \\
\text { Obrigada, }\end{array}$ \\
\hline 3 & $\begin{array}{l}\text { Olá [deputado/deputada], } \\
\text { Acho que eu já entrei em contato antes, perguntando alguma dúvida. Sou sua } \\
\text { eleitora faz tempo. } \\
\text { Não acompanho muito política, mas como meu filho menor gosta e vive me } \\
\text { perguntando sobre isso, tento acompanhar pra explicar pro garoto. } \\
\text { Eu queria saber como foi esta história de reforma política, que foi votada estes } \\
\text { dias. } \\
\text { É tanta coisa que sai no jornal, que a gente fica confusa. Foi boa ou foi ruim? Você } \\
\text { foi contra ou a favor? } \\
\text { Abraços, }\end{array}$ \\
\hline 4 & $\begin{array}{l}\text { Olá [Deputado/Deputada], } \\
\text { Eu queria entender melhor como foi esta história da redução da maioridade penal. } \\
\text { Foi aprovada ou rejeitada, como ficou no fim das contas? Como você votou? } \\
\text { Obrigada. Abraços, }\end{array}$ \\
\hline
\end{tabular}

Fonte: Elaborado pelos autores. Base de dados do projeto: "Elites parlamentares e tecnologias digitais de uma perspectiva comparada" (Geist). 
Tabela 4

Teste Ancova, modelo 1

\begin{tabular}{|c|c|c|c|c|c|c|c|}
\hline \multirow[b]{2}{*}{ Parameter } & \multirow[b]{2}{*}{ B } & \multirow[b]{2}{*}{$\begin{array}{l}\text { Std. } \\
\text { Error }\end{array}$} & \multicolumn{2}{|c|}{$\begin{array}{c}95 \% \text { Wald } \\
\text { Confidence Interval }\end{array}$} & \multicolumn{3}{|c|}{ Hypothesis Test } \\
\hline & & & Lower & Upper & $\begin{array}{c}\text { Wald } \\
\text { Chi- } \\
\text { Square }\end{array}$ & df & Sig. \\
\hline (Intercept) & 3,794 & 1,5208 &, 813 & 6,775 & 6,223 & 1 & 013 \\
\hline $\begin{array}{l}\text { [Tratamento }=\text { com } \\
\text { incentivos] }\end{array}$ & $-2,018$ & ,3334 & $-2,671$ & $-1,365$ & 36,637 & 1 &, 000 \\
\hline $\begin{array}{l}\text { [Tratamento }=\text { sem } \\
\text { incentivos] }\end{array}$ & $0^{a}$ & & & & & & \\
\hline Idade &,- 019 & ,0109 &,- 040 &, 003 & 2,958 & 1 & ,085 \\
\hline Sexo &, 021 & ,2224 &,- 415 & ,457 &, 009 & 1 & 924 \\
\hline Escolaridade &,- 042 & ,0968 &,- 231 & 148 & 185 & 1 &, 667 \\
\hline Ocupação profissional &, 059 &, 1081 &,- 153 &, 271 & ,296 & 1 &, 587 \\
\hline Títular / Suplente &,- 275 &, 3839 & $-1,027$ & ,477 &, 513 & 1 &, 474 \\
\hline Partido &, 005 &, 0168 &,- 028 & ,038 & ,097 & 1 &, 756 \\
\hline Ideologia &, 028 &, 1656 &,- 296 &, 353 &, 030 & 1 &, 863 \\
\hline Tamanho do partido &,- 002 & ,0055 &,- 013 & ,009 & 173 & 1 &, 677 \\
\hline Governo / Oposição &, 000 &, 0056 &,- 011 &, 011 &, 002 & 1 &, 961 \\
\hline Protagonismo &,- 777 & ,3536 & $-1,470$ &,- 084 & 4,828 & 1 &, 028 \\
\hline Magnitude do distrito &, 009 & ,0096 &,- 009 & ,028 &, 950 & 1 &, 330 \\
\hline Competição eleitoral & ,216 & ,3768 &,- 523 &, 954 & ,328 & 1 &, 567 \\
\hline Densidade eleitoral & 3,758 & 6,2794 & $-8,549$ & 16,066 & ,358 & 1 &, 550 \\
\hline Concentração eleitoral &, 526 & 1,0779 & $-1,586$ & 2,639 & ,238 & 1 &, 625 \\
\hline Receitas de campanha &, 054 &, 0347 &,- 014 &, 122 & 2,432 & 1 &, 119 \\
\hline (Scale) & $1^{\mathrm{b}}$ & & & & & & \\
\hline \multicolumn{8}{|c|}{ Dependent Variable: Respondido } \\
\hline \multirow{2}{*}{\multicolumn{8}{|c|}{ a. Set to zero because this parameter is redundant. }} \\
\hline & & & & & & & \\
\hline
\end{tabular}

Fonte: Elaborado pelos autores. Base de dados do projeto: "Elites parlamentares e tecnologias digitais de uma perspectiva comparada" (Geist). 
Tabela 5

Teste Ancova, modelo 2

\begin{tabular}{|c|c|c|c|c|c|c|c|}
\hline \multirow[b]{2}{*}{ Parameter } & \multirow[b]{2}{*}{ B } & \multirow[b]{2}{*}{$\begin{array}{l}\text { Std. } \\
\text { Error }\end{array}$} & \multicolumn{2}{|c|}{$\begin{array}{c}95 \% \text { Wald } \\
\text { Confidence Interval }\end{array}$} & \multicolumn{3}{|c|}{ Hypothesis Test } \\
\hline & & & Lower & Upper & $\begin{array}{c}\text { Wald } \\
\text { Chi- } \\
\text { Square }\end{array}$ & df & Sig. \\
\hline (Intercept) & 2,474 & 1,2429 &, 038 & 4,910 & 3,963 & 1 &, 046 \\
\hline $\begin{array}{l}\text { [[Tratamento }=\text { período } \\
\text { eleitoral }]\end{array}$ &,- 826 & ,2328 & $-1,283$ &,- 370 & 12,603 & 1 & ,000 \\
\hline $\begin{array}{l}{[[\text { Tratamento }=\text { período }} \\
\text { não eleitoral }]\end{array}$ & $0^{a}$ & & & & & & \\
\hline Idade &,- 017 & ,0096 &,- 036 &, 002 & 3,071 & 1 &, 080 \\
\hline Sexo &,- 028 & 1835 &,- 387 & ,332 & ,023 & 1 & 881 \\
\hline Escolaridade &,- 049 & 0865 &,- 218 &, 121 & ,319 & 1 &, 572 \\
\hline Ocupação profissional & 121 & ,0933 &,- 062 &, 304 & 1,686 & 1 &, 194 \\
\hline Títular / Suplente &,- 297 & ,3433 &,- 970 & ,376 & ,748 & 1 &, 387 \\
\hline Partido &,- 009 &, 0142 &,- 036 & ,019 & ,358 & 1 &, 550 \\
\hline Ideologia &, 027 & 0986 &,- 167 &, 220 &, 073 & 1 &, 787 \\
\hline Tamanho do partido &, 002 & ,0049 &,- 008 &, 012 & 167 & 1 &, 682 \\
\hline Governo / Oposição &, 002 &, 0050 &,- 008 &, 012 &, 149 & 1 &, 700 \\
\hline Protagonismo &,- 574 &, 3369 & $-1,234$ &, 087 & 2,900 & 1 &, 089 \\
\hline Magnitude do distrito &, 009 & ,0085 &,- 008 &, 026 & 1,114 & 1 & ,291 \\
\hline Competição eleitoral & ,321 & ,3068 &,- 280 & ,923 & 1,098 & 1 & 295 \\
\hline Densidade eleitoral & 1,372 & 5,4691 & $-9,347$ & 12,091 &, 063 & 1 & 802 \\
\hline Concentração eleitoral &,- 193 &, 8822 & $-1,922$ & 1,536 &, 048 & 1 & 827 \\
\hline Receitas de campanha &, 032 & ,0265 &,- 020 &, 084 & 1,473 & 1 &, 225 \\
\hline (Scale) & $1^{\mathrm{b}}$ & & & & & & \\
\hline \multicolumn{8}{|c|}{ Dependent Variable: Respondido } \\
\hline \multicolumn{8}{|c|}{ a. Set to zero because this parameter is redundant. } \\
\hline \multicolumn{8}{|c|}{ b. Fixed at the displayed value. } \\
\hline
\end{tabular}

Fonte: Elaborado pelos autores. Base de dados do projeto: "Elites parlamentares e tecnologias digitais de uma perspectiva comparada" (Geist). 
Tabela 6

Teste Ancova, modelo 3

\begin{tabular}{|c|c|c|c|c|c|c|c|}
\hline \multirow[b]{2}{*}{ Parameter } & \multirow[b]{2}{*}{ B } & \multirow[b]{2}{*}{$\begin{array}{l}\text { Std. } \\
\text { Error }\end{array}$} & \multicolumn{2}{|c|}{\begin{tabular}{c|}
$95 \%$ Wald \\
Confidence Interval
\end{tabular}} & \multicolumn{3}{|c|}{ Hypothesis Test } \\
\hline & & & Lower & Upper & $\begin{array}{c}\text { Wald } \\
\text { Chi- } \\
\text { Square }\end{array}$ & df & Sig. \\
\hline (Intercept) & 105 & 9896 & $-1,835$ & 2,045 & 011 & 1 & 915 \\
\hline$[[$ Tratamento $=$ e-mail $]$ & 1,860 & 2065 & 1,456 & 2,265 & 81,165 & 1 & 0,000 \\
\hline $\begin{array}{l}{[[\text { Tratamento }=} \\
\text { Facebook }]\end{array}$ & $0^{\mathrm{a}}$ & & & & & & \\
\hline Idade & 013 & 0077 &,- 002 & 028 & 2,737 & 1 & 098 \\
\hline Sexo &,- 104 & 1414 &,- 381 & 173 & 540 & 1 & 463 \\
\hline Escolaridade &,- 073 & 0750 &,- 220 & 074 & 956 & 1 & 328 \\
\hline Ocupação profissional & 158 & 0772 & 007 & 310 & 4,201 & 1 & 040 \\
\hline Títular / Suplente & 101 & 3438 &,- 573 &, 774 & 086 & 1 & 770 \\
\hline Partido &,- 020 & 0115 &,- 042 & 003 & 2,921 & 1 & 087 \\
\hline Ideologia & 033 & 0449 &,- 055 & 121 & 529 & 1 & 467 \\
\hline Tamanho do partido &, 009 & 0049 &,- 001 & 018 & 3,077 & 1 & 079 \\
\hline Governo / Oposição &, 003 & ,0038 &,- 005 & 010 & ,494 & 1 & ,482 \\
\hline Protagonismo &,- 351 & ,3402 & $-1,018$ & ,316 & 1,064 & 1 &, 302 \\
\hline Magnitude do distrito &,- 005 & 0075 &,- 020 & 010 & 427 & 1 &, 514 \\
\hline Competição eleitoral & 228 & 2285 &,- 220 & 676 & 996 & 1 & 318 \\
\hline Densidade eleitoral & $-3,231$ & 4,5965 & $-12,240$ & 5,778 & 494 & 1 & 482 \\
\hline Concentração eleitoral & 124 & ,7754 & $-1,396$ & 1,644 & 026 & 1 & 873 \\
\hline Receitas de campanha & 001 & 0152 &,- 029 &, 031 &, 005 & 1 & 945 \\
\hline (Scale) & $1^{\mathrm{b}}$ & & & & & & \\
\hline \multicolumn{8}{|c|}{ Dependent Variable: Respondido } \\
\hline
\end{tabular}

Fonte: Elaborado pelos autores. Base de dados do projeto: "Elites parlamentares e tecnologias digitais de uma perspectiva comparada" (Geist). 


\begin{abstract}
Do politicians answer voters' questions? An experiment controlling incentives of message, period, and medium

This article presents the results of an experiment conducted between September 2014 and July 2015 to check the responsiveness of Brazilian congressmen to questions submitted by citizens under various conditions. A series of messages were sent over the period, controlling incentives. We tested three factors: a) the message content (potential voter versus a question on issues that are the subject of political debate); b) the period in which the message was sent (during or not during electoral campaigns); c) the platform through which the message was sent (email and social media). The logistic regression model shows: i) the election period does not have a significant influence; ii) incentives in message content increase tenfold the probability of receiving a response; iii) messages sent via social media increase nine times the probability of response. Overall, the response rate is very low, indicating the low responsiveness of Brazilian deputies. We discuss these results drawing on the theory of political incentives and the possibilities of accountability that have emerged with online political communication tools. We believe that the present research paves the way for future experimental approaches in this area.
\end{abstract}

Keywords: experiment; legislation; interactivity; accountability; Facebook

\title{
Resumen
}

¿Los políticos responden a los cuestionamentos de los electores? Un experimento controlando los incentivos de mensaje, período y medio

Este artículo presenta los resultados de un experimento llevado a cabo entre septiembre de 2014 y julio de 2015 para comprobar la capacidad de respuesta del Congreso brasileño a las cuestiones planteadas por los ciudadanos en diferentes condiciones. Para ello, se enviaron una serie de mensajes durante el período, controlando los incentivos. Hemos probado tres factores: a) el contenido del mensaje (potencial votante vs. pregunta sobre la votación de un proyecto de ley en el plenario); b) el período en que se envió el mensaje (electoral y no electoral); c) la plataforma a través de la cual se envió el mensaje (correo electrónico y medios sociales). El modelo de regresión logística muestra que el período electoral no ejerce gran influencia, que los incentivos en el contenido del mensaje aumentan diez veces la probabilidad de respuesta y los mensajes enviados a través de las redes sociales aumentan nueve veces la probabilidad de respuesta. En general, la tasa de respuesta es muy baja, lo que indica la poca capacidad de respuesta de los diputados brasileños. Discutimos los resultados a la luz de la teoría de los incentivos políticos y las posibilidades de accountability aportadas por las herramientas de comunicación política en línea. Creemos que la investigación abre el camino para futuros enfoques experimentales en esta área.

Palabras-clave: experimento; legislativo; interactividad; capacidad de respuesta; Facebook

\section{Résumé}

Les politiciens répondent aux questions des électeurs? Une expérience vérifiant des incitations de message, de période et de moyen

Cet article présente les résultats d'une expérience menée entre septembre 2014 et juillet 2015 pour vérifier la réactivité des activités du congrès brésilien aux questions posées par les citoyens dans différentes conditions. Pour cela, une série de messages ont été envoyés au cours de cette période, contrôlant les incitations. Nous avons testé trois facteurs: a) le contenu du message (électeur potentiel par rapport à une question sur le vote d'un projet de loi à I'assemblée); b) l'époque à laquelle le message a été envoyé (période électorale ou non); c) la plate-forme à travers laquelle le message a été envoyé (courrier électronique et médias sociaux). Le modèle de régression logistique démontre que la période électorale n'exerce pas de grande influence, que les incitations dans le contenu du message multiplient par dix la probabilité de réponse et les messages envoyés via les médias sociaux multiplient par neuf la probabilité de réponse. Dans l'ensemble, le taux de réponse est très faible, ce qui indique la faible réactivité des députés brésiliens. Nous discutons les résultats à la lumière de la théorie des incitations politiques et des possibilités de accountability apportées par les outils de communication politique en ligne. Nous croyons que la recherche ouvre la voie aux approches expérimentales futures dans ce domaine.

Mots-clés: expérience; législatif; interactivité; réactivité; Facebook

Artigo submetido à publicação em 16 de junho de 2017. Versão final aprovada em 26 de junho de 2018.

Opinião Pública adota a licença Creative Commons CC-BY.

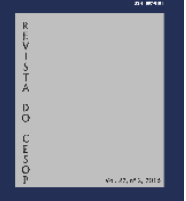

